\title{
Stock Returns with Consumption and Illiquidity Risks
}

\author{
Elena Márquez \\ (Universidad Complutense de Madrid) \\ Belén Nieto \\ (Universidad de Alicante) \\ Gonzalo Rubio \\ (Universidad CEU Cardenal Herrera)
}

September 5, 2012

Key words: Stochastic discount factor; ultimate consumption risk; market-wide liquidity; illiquidity premium.

\section{JEL: G10, G12, E44}

Authors acknowledge financial support from IVIE (Instituto Valenciano de Investigaciones Económicas). Belén Nieto acknowledges financial support from Ministerio de Educación y Ciencia grant ECO201129751, and Gonzalo Rubio (gonzalo.rubio@uch.ceu.es) recognizes the support from Ministerio de Economía y Competitividad grant ECO2012-34268, Generalitat Valenciana grant PROMETEO/2008/106, and from Copernicus4/2011. The authors thank seminar participants at the XVI Foro de Finanzas, ESADE, the Sixth Research Workshop on Asset Pricing at Instituto de Empresa Business School, the 2009 Annual Conference of the European Financial Management Association, and the $39^{\text {th }}$ Annual Meeting of the European Finance Association. The authors especially thank the constructive comments of Yakov Amihud, José Manuel Campa, Carl Chen, Hanno Lustig, Francisco Peñaranda, Luis Sarto, Carles Vergara, and two anonymous referees. We assume full responsibility for any remaining errors.

Corresponding author: Gonzalo Rubio, Department of Economics and Business, Universidad CEU Cardenal Herrera, Valencia, Spain (gonzalo.rubio@uch.ceu.es) 


\begin{abstract}
This paper derives closed-form expressions for consumption-based stochastic discount factors adjusted by market-wide illiquidity shocks, considering both contemporaneous and ultimate consumption risk. We find that market-wide illiquidity risk is important for pricing risky assets under alternative preference specifications, although it is especially relevant when we allow for ultimate consumption risk. We also find a large and highly significant illiquidity risk premium for the first quarter of the year suggesting a timevarying behaviour of the market-wide illiquidity premium.
\end{abstract}




\section{Introduction}

The economic understanding of the stock markets behaviour is based on the fact that investors dislike stocks because they tend to do badly -reducing consumption ultimately- in economic downturns and especially on recessions. Although this foundation made consumption-based asset pricing models very popular, their systematic empirical rejection has led to new models in which utility depends not only on consumption but also on other arguments which enter the utility function in a nonseparable fashion. Well-known models with habit persistence or recursive utility functions are good examples. Because of the non-separability, marginal utility of consumption responds to changes in state variables making the countercyclical behaviour of the stochastic discount factor (SDF hereafter) more pronounced.

In this framework, different papers have shown the relevance of some state variables that are constrained to a slow adjustment; this is the case of labour income growth, habits, housing collateral or the share of housing consumption in total consumption. This insight, together with the cost of adjusting consumption itself, suggests that the basic consumption-based model may hold at long-horizons. Indeed, a recent line of research explores this field. Jagannathan and Wang (2007) find that the basic consumption-based model can account relatively well for annual frequency data being the relevant data those corresponding to the fourth quarter of each year. And Parker and Julliard (2005) argue that changes in wealth have a delayed effect on consumption patterns. Hence, the covariance between portfolio returns and consumption growth over the quarter of the return and many following quarters (ultimate 
consumption) is needed for conciliating expected returns and consumption risk. ${ }^{1}$ The dynamics of the long-run consumption growth results in an ultimate consumption risk SDF with a counter-cyclical behaviour much more pronounced than the one observed for the contemporaneous consumption growth model. The model has some success in explaining the pricing of size and book-to-market portfolios, although it is unable to fit the extreme small-value and small-growth stocks portfolios.

Given this discussion, we propose a fundamental consumption-based model in the line of the Parker and Julliard (2005) ultimate consumption framework. We take advantage of the long-run consumption risk but improving the counter-cyclical pattern of the SDF considering other pertinent state variables. Of course, the identification of the additional proper state variables is crucial. Our theoretical proposal considers two state variables; the market return, as a consequence of assuming recursive preferences instead of the standard power utility function, and an aggregate illiquidity factor.

The market liquidity role in asset pricing has extensively been analyzed in the literature. The papers by Chordia, Roll and Subrahmanyam (2000) and Hasbrouck and Seppi (2001) could be considered the starting point on this research line. Their main results show that the time-varying liquidity for individual stocks has common systematic components suggesting the possibility of a market-wide liquidity variable being a priced aggregate factor. Amihud (2002) shows that the level of market-wide liquidity affects expected returns and, among others, Pastor and Stambaugh (2003), Acharya and Pedersen (2005), Sadka (2006), Liu (2006), and Korajczk and Sadka

\footnotetext{
${ }^{1}$ Note that this is different from the long-run consumption model of Bansal and Yaron (2004), and Hansen, Heaton and Li (2008) who propose an asset pricing framework with time-varying expectations on future consumption growth under Epstein and Zin (1991) recursive preferences with either higher than one or unitary intertemporal elasticity of substitution respectively. In this model, key shocks moving stock prices are changing expectations of long-run consumption growth and its volatility where there is a persistent predictable component of consumption growth.
} 
(2008) find that the covariance between returns and some measure of aggregate liquidity shocks is significantly priced by the market. Lastly, Watanabe and Watanabe (2008) show that the liquidity risk premium is time varying. They report a large liquidity premium for states with particularly large liquidity betas and argue that their result is consistent with investors facing uncertainty about their trading counterparties' preferences.

Rather surprisingly, however, all previous papers simply include an additional market-wide illiquidity factor to traditional portfolio-based asset pricing models. None of these papers theoretically justify why such a factor may be priced in the market. ${ }^{2}$ This paper covers this gap by deriving closed-form expressions for contemporaneous and ultimate consumption-based stochastic discount factors adjusted by exogenous marketwide illiquidity shocks. In particular, we propose a model in which the aggregate liquidity risk factor arises as a result of illiquidity shocks affecting the investor budget constraint when solving the investor optimization problem. We then obtain a closedform expression for a consumption-based SDF adjusted by aggregate liquidity. To the best of our knowledge, this papers reports for the first time how aggregate illiquidity behaves together with consumption growth risk. Our evidence suggests that aggregate illiquidity is indeed important in pricing risky stocks in models with ultimate consumption risk, and that these adverse shocks are particularly relevant during the first quarter of the year.

This paper is organized as follows. Section 2 derives our three-factor asset pricing model with market-wide consumption and illiquidity risk under recursive

\footnotetext{
${ }^{2}$ Of course, we recognize the relevant contributions of Acharya and Pedersen (2005), and Watanabe and Watanabe (2008) who introduce illiquidity shocks by subtracting an illiquidity cost from the asset return. Their approach can also to be understood as an alternative way to incorporate illiquidity shocks via the budget constraint.
} 
preferences, while Section 3 contains a description of data. Section 4 discusses the estimation strategy, and reports the empirical results. Section 5 concludes with a summary of our main findings.

\section{The Consumption-based Liquidity-adjusted Stochastic Discount Factor}

All the empirical papers concerning the existence of a liquidity market-wide factor are based on the implicit assumption that there exists a SDF that depends on some measure of aggregate liquidity. To be explicit about how systematic liquidity enters the SDF is not an easy task. He and Modest (1995) argue that a combination of short-selling, borrowing and solvency constraints together with trading costs frictions can generate a wedge between the SDFs and asset prices large enough to make some well-known empirical puzzles compatible with equilibrium in financial markets. Indeed, Lustig and Van Niewerburgh (2005) explore a model in which shocks in the housing market affecting housing collateral determine the size of the wedge between prices and the marginal rate of intertemporal substitution of consumption.

In this paper, we do not include the market-wide liquidity measure as an argument of the utility function. Instead, we assume that shocks to aggregate liquidity directly affect the representative agent intertemporal budget constraint. In that way, future market-wide liquidity conditions will affect future aggregate consumption and, therefore, how investors value today future payoffs.

Assuming recursive preferences as in Epstein and Zin (1991)

$$
U_{t} \equiv\left[(1-\beta) C_{t}^{1-\rho}+\beta\left[E_{t}\left(U_{t+1}^{1-\gamma}\right)\right]^{1-\rho}\right]^{\frac{1}{1-\rho}},
$$


the representative agent would take his consumption-investment decision by solving the following optimization problem,

$$
\begin{aligned}
& \max _{z} U_{t} \\
& \text { s.t. } \\
& C_{t}=e_{t}-z p_{t} \\
& C_{t+1} / \phi\left(L_{t+1}\right)=e_{t+1}+z X_{t+1}
\end{aligned}
$$

where $U_{t}$ denotes utility at time $t, C_{t}$ is the aggregate consumption at time $t, \beta$ is the subjective discount factor, $\gamma$ represents the coefficient of relative risk aversion, $\rho$ is the inverse of the elasticity of intertemporal substitution, $e_{t}$ is the consumption endowment at time $t, z$ is the amount invested today in the asset, $p_{t}$ is the price today of the asset, and $X_{t+1}$ is the payoff of the asset at $t+1$. Finally, $\phi\left(L_{t+1}\right)$ is a function of the aggregate illiquidity shocks that affects the investor's budget constraint. This function takes the value of 1 in normal times, a value lower than 1 if market-wide liquidity is high, and a value greater than 1 when an adverse illiquidity shock impact the economy. Hence, when a future adverse illiquidity shock is expected, $\phi\left(L_{t+1}\right)>1$, future consumption will be negatively affected. In this way, the same asset future payoff will have today a higher value in terms of future consumption when the liquidity of the market is low. On the contrary, when there is no illiquidity shocks in the market, $\phi\left(L_{t+1}\right)=1$, and investors support the standard budget constraint. Thus, when the market is more illiquid, this is, just before or at the beginning of recessions, the SDF will be expected to be higher than the one generated by the standard problem intensifying the desirable countercyclical time series property of this variable.

Solving problem (1), the following Euler equation is obtained, ${ }^{3}$

\footnotetext{
${ }^{3}$ The details can be found in Appendix A1.
} 


$$
p_{t}=E_{t}\left[M_{L A R, t+1} X_{t+1}\right]
$$

where $M_{L A R, t+1}$ denotes the liquidity-adjusted SDF which is given by

$$
M_{L A R, t+1}=\beta^{\kappa}\left(\frac{C_{t+1}}{C_{t}}\right)^{-\rho \kappa}\left(R_{W t+1}\right)^{\kappa-1} \phi\left(L_{t+1}\right)^{\kappa},
$$

where $\kappa=\frac{1-\gamma}{1-\rho}$, and $R_{W t}$ is the rate of return of aggregate wealth. When there is no illiquidity shocks, i.e. $\phi\left(L_{t+1}\right)=1$, the SDF in equation (3) is the standard SDF under recursive preferences.

$$
M_{R, t+1}=\beta^{\kappa}\left(\frac{C_{t+1}}{C_{t}}\right)^{-\rho \kappa}\left(R_{W t+1}\right)^{\kappa-1}
$$

Therefore, the liquidity adjusted SDF in (3) is just the standard SDF, given by (4), scaled by the function that picks up the effects of aggregate illiquidity shocks on consumption growth. Note that $M_{L A R, t+1}$ will be higher than the correspondent non liquidity-adjusted SDF, $M_{R, t+1}$, precisely in those time periods in which recessions are shortly expected. In other words, we obtain a SDF with the same counter-cyclical behaviour that the one generated by the standard recursive preferences problem but with a stronger cycle pattern.

The main insight of our proposed SDF relies on the negative effect that any aggregate illiquidity shock has on the purchasing power of the representative agent. That is, the illiquidity shock acts as a deflator adjustment just as a deflator operator takes into account an adverse inflation shock. In our theoretical model all variables are expressed in real rather than in nominal terms. An illiquidity shock would imply a reduction in the purchasing power of the representative agent. Hence, for a given payoff, when confronting a negative liquidity shock, the real consumption power of the 
agent must be lower relative to the non-liquidity shock case. That is, the first component of our SDF is the intertemporal marginal rate of substitution of the representative agent, and $\phi\left(L_{t+1}\right)^{\kappa}$ is the liquidity factor associated to the purchasing power constraint rising from aggregate illiquidity shocks. When the purchasing power constraint does not bind, the liquidity factor disappears and payoffs are directly priced from the representative agent's marginal rate of substitution. If the illiquidity factor moves overtime in a counter-cyclical fashion, and if the dispersion among covariances between stock returns and the aggregate illiquidity factor is high enough at the cross-section, the model could potentially perform better than non-liquidity models.

For the case of power utility, the SDF, denoted by $M_{L A P, t+1}$, can be obtained by imposing the equality between the relative risk aversion coefficient and the inverse of the elasticity of intertemporal substitution $(\gamma=\rho)$ in equation (3), ${ }^{4}$

$$
M_{L A P, t+1}=\beta\left(\frac{C_{t+1}}{C_{t}}\right)^{-\gamma} \phi\left(L_{t+1}\right) .
$$

Finally, we also consider the specification under ultimate consumption risk as in Parker and Julliard (2005). They propose a SDF that relates marginal utility in period $t$ with marginal utility in period $t+1+S$. In that way, investors take the expectation about far away future consumption into account when taking investment decisions today. Applying the same idea, we derive the liquidity-adjusted SDFs for both power and recursive preferences. The resulting expressions, respectively, are given by: ${ }^{5}$

$$
M_{L A P, t+1}^{S}=\beta^{S+1}\left(\frac{C_{t+1+S}}{C_{t}}\right)^{-\gamma} \phi\left(L_{t+1, t+1+S}\right) R_{f t+1, t+1+S}
$$

\footnotetext{
${ }^{4}$ As in the case of recursive preferences, the SDF given by equation (5) becomes the standard utility power SDF for normal market-wide liquidity conditions.

${ }^{5}$ All the details are in Appendix A2.
} 


$$
M_{L A R, t+1}^{S}=\left[\beta^{S+1}\left(\frac{C_{t+1+S}}{C_{t}}\right)^{-\rho} \phi\left(L_{t+1, t+1+S}\right)\right]^{\kappa} R_{W t+1, t+1+S}^{\kappa-1} R_{f t+1, t+1+S},
$$

where $R_{W t+1, t+1+S}$ and $R_{f t+1, t+l+S}$ denote the cumulative gross return on wealth and on the risk free asset, respectively, from period $t+1$ to period $t+1+S$. This is our three-factor model in which we simultaneously combine consumption, market, and market-wide illiquidity risks with ultimate risk.

It must be noted that equations (6) and (7) nest the correspondent standard (non liquidity-adjusted) SDFs under ultimate risk for power and recursive preferences, respectively, when $\phi\left(L_{t+1, t+1+S}\right)=1$. Obviously, equations (6) and (7) also nest equations (5) and (3), respectively, when $S=0$. Finally, and as before, equation (6) is a particular case of (7) when $\gamma=\rho$.

In this paper, we test the different consumption-based liquidity-adjusted models embodied by equation (7). Our conjecture is that this type of specifications should be able to better explain the cross-sectional variation of average returns than other previously analyzed models have done. Note that we are able to perform an empirical comparison among all these models since all of them are nested by equation (7). Ultimately, we want to test whether expression (7) mirror macroeconomic conditions better than non-liquidity adjusted models.

\section{Data}

For the period 1963:I to 2010:IV, we collect quarterly seasonally adjusted aggregate real per capita consumption expenditure of non-durables and services from National Income and Product Accounts (NIPA) given in Table 7.1. Monthly value-weighted stock market return and risk-free rate are taken from Kenneth French's web page, from 
which we compute quarterly returns. The price deflator from NIPA Table 2.8.4 is used to calculate real rates of returns. We also compute quarterly returns of 25 size/book-tomarket value-weighted portfolios, 17 industry portfolio returns, 10 dividend-yield and 10 momentum portfolio returns from the monthly figures available at Kenneth French's web page.

A traditional debate on the asset pricing literature discusses the empirical proxy that is used to measure illiquidity. Besides the well known bid-ask spread, popular proxies associate the size of the trade with the size of the price change. This price impact approach is based on the classic theoretical paper of Kyle (1985), which linearly relates the net order flow to the price variation. Two widely used proxies of the price impact are due to Amihud (2002) who proposes the ratio of absolute return to dollar trading volume, and to Pastor and Stambaugh (2003) who measure liquidity by the amount in which returns rebound upon high volume. ${ }^{6}$

In order to empirically approximate our illiquidity function, this paper computes both the Amihud (2002) and the Pastor-Stambaugh (2003) proxies of aggregate illiquidity. Among others, the Amihud (2002) ratio has been used by Acharya and Pedersen (2005), Korajczyk and Sadka (2008), Kamara, Lou and Sadka (2008), and Watanabe and Watanabe (2008). From a practical point of view, the main advantage of the Amihud's illiquidity ratio is that it can be easily computed for a long time period because it depends only on daily rates of returns and trading volume. This is clearly relevant for testing asset pricing models.

\footnotetext{
${ }^{6}$ These two proxies assume that the price impact of buys and sell are symmetric. See Brennan, Chordia, Subrahmanyam, and Tong (2012) for an analysis of the asymmetric effects of sell-side and buy-side illiquidity on the cross-section of average returns.
} 
For the Amihud (2002) illiquidity measure, we first obtain the individual stocks illiquidity, which is calculated as the ratio of the absolute value of daily return over the dollar volume. This illiquidity measure is estimated daily at the individual level as,

$$
\operatorname{Illiq}_{j, d}=\frac{\left|R_{j, d}\right|}{D V o l_{j, d}},
$$

where $\left|R_{j, d}\right|$ is the absolute return of asset $j$ on day $d$, and $D V o l_{j, d}$ is the dollar volume of asset $j$ during day $d$.

This measure is aggregated over all days for each month in the sample period to obtain an individual illiquidity measure for each stock at month $t$,

$$
\text { Illiq }_{j, t}=\frac{1}{D_{j, t}} \sum_{d=1}^{D_{j, t}} \frac{\left|R_{j, d}\right|}{D V o l_{j, d}},
$$

where $D_{j, t}$ is the number of days for which data are available for stock $j$ in month $t^{7}$

Finally, using all $N$ available stocks, we obtain the market-wide illiquidity measure as the cross-sectional average of expression (9) for each month in the sample period as,

$$
I L L I Q_{m, t}=\frac{1}{N} \sum_{j=1}^{N} \operatorname{Illiq}_{j, t}
$$

\footnotetext{
${ }^{7}$ We thank Yakov Amihud for kindly providing his data until December 1996. We update his measure from January 1997 to December 2010 using daily data from CSRP on all individual stocks with enough data within a given month. At least 15 observations of the ratio within the considered month are required for asset $j$ to be included in the sample. An exception has been made for September 2001 requiring at least 12 observations in this case.
} 
Using the value of the aggregate illiquidity ratio given by equation (10) for the last month in each quarter, we compute our function representing market illiquidity shocks as the residual from an $A R(1)$ process. $^{8}$ Finally, $\phi\left(L_{t}\right)$ is defined as the gross standardized residual from the autoregressive regression. ${ }^{9}$

As an alternative measure of market-wide liquidity, we employ the PastorStambaugh (2003) liquidity proposal which is based on daily regressions for individual stock excess returns over the market return in a calendar month,

$$
R_{j, t+1}^{e m}=a+b R_{j, t}+g\left\lfloor\operatorname{sign}\left(R_{j, t}^{e m}\right)\right\rfloor D V o l_{j, t}+e_{j, t+1}
$$

where $R_{j, t+1}^{e m}$ denotes the return of stock $j$ over the market return. Pastor and Stambaugh aggregate $g$ across stocks and scale it for growing dollar volume. They finally propose the innovations as the final measure of liquidity. ${ }^{10}$ The intuition is that high volume moves prices away equilibrium and they rebound the following day which suggests that $g$ is typically negative. From the innovations of an $A R(1)$ process, we standardize the residual, so that $\phi\left(L_{t}\right)$ is defined as one less the standardized residual. In this way, the two measures that we use move around 1, where amounts higher than 1 indicate higher illiquidity, and values lower than 1 implies higher liquidity.

Figure 1 shows the counter-cyclical behaviour of our two approximations of the illiquidity function. The shaded regions in Figure 1 are U.S. macroeconomic recessions

\footnotetext{
${ }^{8}$ Unlike the $A R(2)$ model usually employed in literature when using monthly data, we employ the $A R(1)$ specification with quarterly data. The residuals from the $A R(1)$ model, our illiquidity-shock measure, have a first-order autocorrelations of only -0.073 . It should also be pointed out that the effect of detrending the autoregressive regressions using the ratio of market capitalizations between two adjacent periods is negligible.

${ }^{9}$ In order to get values of our illiquidity measure closely resembling units of rates of returns, the residuals have been standardized dividing by ten times its sample standard deviation. Then, we add up one in order to have the gross standardized residual.

${ }^{10}$ The monthly series are available in Lubos Pastor's web site.
} 
from peak to trough as defined by the National Bureau of Economic Research (NBER). Both measures tend to increase during or before recessions. It is interesting to note the relatively stable behaviour of the illiquidity functions between 2003 and 2007, and the increases of both measures during the last financial crisis. Amihud's measure shows higher peaks than the Pastor-Stambaugh measure during the oil crisis of the seventies and also at the beginning of the nineties. However, the Pastor-Stambugh aggregate illiquidity presents much higher peaks than the Amihud illiquidity during the recent financial turmoil.

\section{Estimation Strategy and Empirical Results}

As previously mentioned, we estimate and compare the asset pricing models nested under the SDF specification given by equation (7):

$$
M_{L A R, t+1}^{S}=\left[\beta^{S+1}\left(\frac{C_{t+1+S}}{C_{t}}\right)^{-\rho} \phi\left(L_{t+1, t+1+S}\right)\right]^{\kappa} R_{W t+1, t+1+S}^{\kappa-1} R_{f t+1, t+1+S}
$$

They are the following: (i) the standard CCAPM, when $S=0, \gamma=\rho$ and $\phi(L)=1$; (ii) the ultimate consumption risk version of the standard CCAPM, when $S>0$, $\gamma=\rho$ and $\phi(L)=1$; (iii) the liquidity-adjusted CCAPM, when $S=0$ and $\gamma=\rho$; (iv) the ultimate consumption risk version of the liquidity-adjusted CCAPM, when $S>0$ and $\gamma=\rho$; (v) the Epstein-Zin model (recursive), when $S=0$ and $\phi(L)=1$; (vi) the ultimate risk specification of the Epstein-Zin model, when $S>0$ and $\phi(L)=1$; (vii) the liquidityadjusted Epstein-Zin model, when $S=0$; and (viii) the ultimate risk version of the 
liquidity-adjusted Epstein-Zin model, in which the SDF is given by equation (7) without restrictions. $^{11}$

We employ the Fama-MacBeth (1973) two-step procedure to estimate the corresponding beta versions of the model. ${ }^{12}$ Hence, we estimate the following OLS cross-sectional regression at each moment of time:

$$
R_{j t}-R_{f t}=\gamma_{0}+\gamma_{1} \beta_{j c t}+\gamma_{2} \beta_{j \phi t}+\gamma_{3} \beta_{j W t}+e_{j t}
$$

where the explanatory variables are the sensitivities of the asset returns to changes in non-durable consumption growth, market illiquidity shocks and the return on aggregate wealth. These betas are estimated with a time-series regression using a moving-data set prior to each cross-sectional regression. When the linearized versions of the models are tested, the three factors are always expressed in logarithm terms.

We employ two sets of test assets: the 25 size/book-to-market Fama-French portfolios and a set of 42 portfolios containing the 25 Fama-French portfolios plus 17 industry portfolios. This second set of portfolios is used to mitigate the important concern raised by Lewellen, Nagel and Shanken (2010). In order to test for the robustness of the results, we also extend the 25 Fama-French portfolios with either 10 dividend-yield-sorted portfolios or 10 momentum-sorted portfolios.

The different models have been estimated for different time horizons $(S=0,3,7$, 11 and 15 quarters ahead). Consistent with Parker and Julliard (2005), the larger explanatory power for both methodologies is obtained for $S=11$. To save space, we just

\footnotetext{
${ }^{11}$ Note that the general specification given by equation (7) also nests the four corresponding versions of the CAPM when the relative risk aversion equals one.

${ }^{12}$ Appendix B contains the formal derivation of the linear specifications corresponding to equation (7).
} 
report the results based on $S=11 .^{13}$ And to make the estimation results for $S=0$ and $S=11$ comparable, given that the long-run specifications need growth rates of the risk factors from now to 3 years ahead, the sample period for the estimation ends at the first quarter of 2008.

As an illustration, Figure 2 shows the contemporaneous SDF under recursive preferences with and without illiquidity shocks for both proxies of our illiquidity function. As expected, the SDF path is clearly counter-cyclical, being especially accentuated when the market-wide illiquidity shocks are considered. This is precisely the time-varying behaviour we would like to find in any SDF potentially able to explain the cross-section and time-varying behaviour of stock returns.

\subsection{Size, Value, and Market-Wide Illiquidity}

Panel A of Table 1.a contains the sample mean and standard deviation of excess returns of the 25 Fama-French portfolios showing the well-known empirical facts about these portfolios. Between 1963:II and 2008:I, both small and high book-to-market firms have larger average returns than other portfolios within the same category. The highest average return is obtained for portfolio 15 , where the smallest firms and the highest book-to-market stocks are simultaneously located. These patterns are displayed in Figure 3.a. However, the highest risk is found in the small but low book-to-market portfolio (portfolio 11).

Panel B reports the return-based illiquidity betas of the 25 Fama-French portfolios using the Amihud market-wide measure of illiquidity. We run time series

\footnotetext{
${ }^{13}$ All results are available from authors upon request.
} 
regressions of the return of each portfolio on our market-wide illiquidity factor. In particular, the estimated regression is given by ${ }^{14}$

$$
R_{j t}=\alpha_{j}+\beta_{j} \phi\left(L_{t}\right)+u_{j t}
$$

As expected, given the economic implications of the market-wide illiquidity factor, we obtain negative and significant coefficients for all portfolios. All portfolio returns are negatively affected by adverse illiquidity shocks. By controlling for book-tomarket, we report monotonically decreasing (more negative) return-based illiquidity betas from big to small firms. On the contrary, when we control for size, we do not observe a monotonic (less negative) pattern when moving from low to high book-tomarket firms. Extreme value firms have a more negative illiquidity beta than mid bookto-market portfolios Interestingly, the illiquidity betas of the extreme low book-tomarket portfolios tend to be more negative than those for high-book-to-market ones. The pattern closely resembles the standard deviation of portfolios sorted by book-tomarket contained in Panel A. Indeed the highest (more negative) illiquidity beta is found for portfolio 11 . Hence, growth and small stocks tend to be strong and negatively affected by market-wide illiquidity shocks. These illiquidity betas, together with the illiquidity betas estimated using the Pastor-Stambaugh market-illiquidity are reported in Figures 3.b and 3.c for size categories within the book-to-market portfolio families, and for the book-to-market sorting within the size families respectively. The illiquidity betas are quite similar as they present the same patterns across size and book-to-market portfolios independently of using the Amihud or the Pastor-Stambaugh measures of aggregate illiquidity.

\footnotetext{
${ }^{14}$ All regressions in this sub-section are OLS autocorrelation-robust standard-error regressions.
} 
Although these previous results are interesting by themselves, we may want to control for both the market portfolio return and non-durable consumption growth when estimating our illiquidity betas. Panel $\mathrm{C}$ of Table 1.a reports the results from the following time-series regressions using the Amihud ratio as market-wide illiquidity

$$
R_{j t}=\alpha_{j}+\beta_{j \phi} \phi\left(L_{t}\right)+\beta_{j W} R_{W t}+\beta_{j c} \Delta C_{t}+u_{j t}
$$

When controlling for book-to-market, we find again a monotonically decreasing (more negative) return-based illiquidity betas from big to small firms for all five bookto-market categories. In particular, small firms are strongly negative and significantly affected by illiquidity shocks. This evidence suggests that illiquidity shocks affects primarily small stocks whatever the value-growth category even after controlling for consumption growth and market return. Although, as shown in Figure 3.a, the mean returns tend to increase from big to small stocks for four book-to-market portfolios, we get just the opposite result for growth stocks. Small stocks, within the growth category, have the lowest average return. This already suggests that any model, even when aggregate illiquidity risk is included given the patterns reported for illiquidity betas, will face with serious problems to price growth stocks, particularly small-growth assets (portfolio 11).

Finally, once we control for size, Panel C of Table 1.a reports a rather smooth $U$ shaped pattern of return-based illiquidity betas from growth to value firms. This is particularly the case for the small portfolios. However, the dispersion of the illiquidity betas from growth to value assets is quite small in comparison with the dispersion previously reported for size-sorted portfolios. This result suggests that our market-wide illiquidity SDF might not be able to account for the value premium. Only when value firms are also relatively small, the liquidity constraints become important. 
Table 1.b contains the same results for the 17 industry portfolios using the Amihud illiquidity proxy. As before, all industries are negatively affected by aggregate illiquidity shocks. This especially true for the following industries: Construction, Machinery, Retail, and Clothes. Similarly, controlling for the market portfolio return and consumption growth, the industries directly affected by market-wide illiquidity shocks are Durable Goods, Construction, Clothes, and Retail Goods.

To further analyze the relationship between aggregate illiquidity and either size or book-to-market, we perform the following regression

$$
\phi\left(L_{t}\right)=\delta_{0}+\delta_{W} R_{W t}^{e}+\delta_{S M B} S M B_{t}+\delta_{H M L} H M L_{t}+u_{t},
$$

where $R_{W t}^{e}$ is the excess return on aggregate wealth, and $S M B$ and $H M L$ are the FamaFrench size and book-to-market factors respectively. We now study whether size and book-to-market risk factors explain market-wide illiquidity as represented by the Amihud illiquidity ratio. The results are reported in Table 2. Regardless of the regression specification, a strongly negative relationship between the market return and the market illiquidity measure is obtained. On the other side, once we control for size and the market, the $H M L$ illiquidity delta coefficient is not longer significantly different from zero. Lastly, the $S M B$ illiquidity delta coefficients are always strongly negative and significant, no matter the considered specification. ${ }^{15}$ As suggested by the analysis of Table 1, these results also indicate that the market-wide liquidity is strongly associated with the size factor but not with the value-growth factor. In other words, aggregate illiquidity shocks particularly affect small stocks rather than value or growth assets, although the regression results using only $H M L$ suggest that market-wide illiquidity risk may affect more growth than value stocks. These results are important to better

\footnotetext{
${ }^{15}$ Similar results are obtained with respect to the Pastor-Stambaugh measure.
} 
understand the empirical results on the cross-sectional variation of average returns reported below.

\subsection{Fama-MacBeth Estimation}

Now we test the general linear three-factor model given by equation (12)

$$
R_{j t}-R_{f t}=\gamma_{0}+\gamma_{1} \beta_{j c t}+\gamma_{2} \beta_{j \phi t}+\gamma_{3} \beta_{j W t}+e_{j t},
$$

where the betas are the sensitivities to consumption growth, illiquidity shocks and the market portfolio returns respectively, and the gammas are the risk premia associated to these aggregate risk factors. These betas are estimated using the well known rolling procedure with the 32 quarters before the corresponding month in the cross-section. This implies that the first quarter available in the cross-sectional results corresponds to 1971:I.

The empirical results, using the Amihud market-wide illiquidity measure, are reported in Tables 3.a and 3.b in which we respectively analyze the Consumption CAPM under power utility, and the Consumption CAPM under recursive preferences. In all cases, we compare the results using either ultimate $(S=11)$ or contemporaneous $(S=0)$ consumption risk specifications, with or without illiquidity shocks. For the two above mentioned tables, Panel A shows the results when we use the 25 Fama-French portfolios, while the expanded set of 42 test assets (including the 17 industry portfolios) is employed for the estimates reported in Panel B.

Panel A of Table 3.a shows that the results for $S=0$ are very disappointing regardless of whether illiquidity shocks are included or not. It is also true however, that the $R$-square increases when market-wide illiquidity is introduced in the regressions. At 
the same time, ultimate consumption risk with illiquidity shocks reduces the magnitude of the intercept with respect to both the specification without market-wide illiquidity and the contemporaneous case. In any case, once we include illiquidity, ultimate consumption risk does not improve the overall fit of the model. Indeed, the overall adjusted $R$-squares tend to be very similar. However, it must be pointed out that the risk premium of market-wide illiquidity is negative and significantly different from zero at the $10 \%$ significance level when the model is estimated under ultimate consumption risk, which is not the case for contemporaneous consumption risk. ${ }^{16}$ This discussion suggests that both ultimate consumption risk and, especially, illiquidity shocks are important to price risky stocks. In any case, the intercept of the second-pass crosssectional regressions is always statistically different from zero indicating the overall rejection of the model. The empirical results regarding the contribution of market-wide illiquidity with respect to the non-illiquidity adjusted model are very similar independently of using 25 or 42 test portfolios. Recall that, given the arguments of Lewellen, Nagel, and Shanken (2010), we may expect that the overall fit of the alternatives specifications may be worse. This is exactly the case. The adjusted $R$ squares tend to be lower in Panel B than in Panel A.

Table 3.b contains further and more complete information by reporting the results from the model under recursive preferences with illiquidity shocks. It is our three-factor linear model in which we simultaneously take into account consumption risk, market risk, and market-wide illiquidity risk. A relevant contribution of the illiquidity risk factor is found when $S=11$. The risk premium of aggregate illiquidity

\footnotetext{
${ }^{16}$ The negative sign of the illiquidity premium makes sense since the derivative of the marginal utility of wealth with respect to illiquidity is positive. When the market experiences a negative illiquidity shock, marginal utility of wealth increases because one additional unit of wealth is highly valued by investors. Of course, the opposite sign would be found if we would employ market-wide liquidity rather than illiquidity.
} 
shocks is negative and significantly different from zero, and the consumption and market risk premia have the expected positive signs although they are not significantly different from zero. The illiquidity risk premium is a large $4.1 \%$ per quarter which indicates the importance of market-wide illiquidity shocks on average returns. ${ }^{17}$ Additionally, the adjusted $R$-squares are also higher relative to Table 3.a. The intuitive and economic explanation of these results can be found in Figure 4 which shows the strong business cycle pattern followed by the SDF for recursive preferences with and without market-wide illiquidity under ultimate risk. The important point, to understand our cross-sectional results, is the higher volatility and the higher peaks before recessions shown by the SDF, once we allow for illiquidity shocks in the ultimate risk SDF specification. However, the intercept remains positive and highly significant pointing out the overall model misspecification. Thus, the average returns of alternative combinations of portfolios are far to be completely explained by either ultimate consumption risk and illiquidity shocks or by market returns and market-wide illiquidity innovations. But the relevant and economically important contribution of market-wide illiquidity shocks should be taken into account in further asset pricing tests. ${ }^{18}$

Figure 5 also shows the improvements in the results. Although, under recursive preferences, portfolios 11 and 15 remain far from the 45 degrees line, the inclusion of both illiquidity risk and ultimate consumption risk slightly improve the adjustment of portfolio 15. This is the case using both the Amihud and the Pastor-Stambaugh measures of aggregate illiquidity. In any case, it should be noted that both portfolios have negative illiquidity betas and lie on the opposite side of the $45^{\circ}$ degree line. This

\footnotetext{
${ }^{17}$ A still high $2.4 \%$ illiquidity premium per quarter is found when we also price industry portfolios. See Panel B of Table 3.b.

${ }^{18}$ In alternative tests with constant full sample period betas we estimate a significant illiquidity risk premia of $5.0 \%$ and $3.6 \%$ with t-statistics of -2.21 and -1.60 for the $25 \mathrm{FF}$ portfolios and the $25 \mathrm{FF}$ and 17 industry portfolios respectively.
} 
reflects how difficult is to price these two portfolios by the same set of risk factors. As we pointed out at the beginning of this section, there are large differences between the liquidity betas for the size-sorted portfolios, while these differences are lower for bookto-market sorted portfolios. So, our market-wide illiquidity factor seems to do a good job in pricing risky assets because its ability to account for size risk, although it seems to be unable to price cross-sectional variation between value and growth stocks.

\subsection{Robustness}

To check for the results of Table 3.b, we repeat the Fama-MacBeth estimation using two different expanded sets of portfolios. The results are reported in Table 4; in Panel A we consider the 25 Fama-French portfolios plus 10 dividend yield portfolios, and in Panel B, 10 momentum portfolios are added to the 25 Fama-French portfolios. The robustness of the results with respect to different test portfolio sets is confirmed. The intercepts are always positive and highly significant, and the illiquidity risk premium, when we employ ultimate risk, is negative and significantly different from zero for both sets of portfolios. It is especially relevant the illiquidity risk premium when we add momentum portfolios to the test assets.

\subsection{Risk Premia Seasonality}

Given the well-known January seasonality of stock returns, we run the following OLS regressions, for both the contemporaneous and ultimate risk specifications.

$$
\hat{\gamma}_{i t}=a+b D_{R Y t}+u_{i t} ; i=1,2,3 \text { and } 4
$$

The dependent variable in (16) is one out of the four coefficients from the estimation of equation (12) with the 25 Fama-French portfolios and the 17 industry portfolios. $D_{R Y t}$ is 
a dummy variable which is equal to one if the observation belongs to either the second, third or fourth quarter of the year, and equals zero otherwise. The estimated intercept is therefore the average risk premia during the first quarter, while the slope coefficients represent the difference between the average risk premia during the rest of the year and the average risk premia during the first quarter.

The results, reported in Table 5, show a strong first quarter seasonality of the illiquidity risk premium for both the contemporaneous and ultimate risk consumption specifications. In particular, the negative and statistically significant risk premium, reported in Table 3.b, for recursive preferences with illiquidity and ultimate risks, is completely due to the first quarter of the year. The same result is obtained for the contemporaneous case; the negative but insignificant risk premium becomes strongly negative and highly significant. We can therefore conclude that the illiquidity risk premium seems to be negative and significant only during the first quarter of the year. In fact, the illiquidity premium for the rest of the year is positive and statistically different from the illiquidity risk premium during the first quarter. These results suggest a strong time-varying behaviour of the illiquidity risk premium. The time-varying behaviour reported by Watanabe and Watanabe (2008) may be just a consequence of the striking seasonality found for the illiquidity risk premium during the first quarter of the year.

There is also some marginally significant evidence of the consumption growth risk premium seasonality for the ultimate consumption risk specification. The difference between this risk premium during the first quarter and the rest of the year presents a tstatistic of -1.81 . However, we find no evidence of market risk premium seasonality once we control for both consumption risk and illiquidity risk. 


\section{Conclusions}

This paper proposes a fundamental consumption asset pricing model by assuming recursive preferences and considering market illiquidity shocks affecting the representative investor budget constraint. In this context, the model is a consumptionbased model in which, apart from the market return, a new state variable related to aggregate illiquidity shocks arises. Differently to other asset pricing papers that consider aggregate liquidity risk, our model is derived by solving the representative consumerinvestor optimization problem under the ultimate consumption risk idea as in Parker and Julliard (2005). Our conjuncture is that this model prices risky assets better than others do because the resulting SDF shows a stronger counter-cyclical pattern.

Our model nests both standard and new model specifications which have been tested for different sets of portfolios. We test the linear version of the models using the traditional Fama and MacBeth (1973) procedure. The best overall results have been got for our three factor model under the ultimate risk specification. In this case, all the risk premia have the expected signs and the illiquidity risk factor is significantly priced. However, and as before, the intercept is significantly different from zero indicating the model misspecification.

We have also found a strong and highly significance evidence of a negative market-wide illiquidity premium during the first quarter of the year. Interestingly, the behaviour of the illiquidity premium seems to change dramatically from a significant negative premium during the first quarter of the year to a positive risk premium for the rest of the year. 
Summarizing, we find that the market-wide illiquidity factor contributes to the improvement of consumption-based SDFs, but the average excess returns of our test assets remain too far of the estimated mean returns. Although our model is able to account for the size premium reasonably, it seems that additional aggregate risk factors are needed in order to fully explain the value premium. The analysis of our illiquidity risk factor shows that the differences of the illiquidity betas for value and growth portfolios are not large enough to generate the necessary cross-sectional variation between average returns of value and growth stocks. This clarifies how difficult it would be to price the extreme portfolios by the same set of risk factors. 


\section{References}

Acharya, V. and L. Pedersen (2005), Asset Pricing with Liquidity Risk, Journal of Financial Economics 77, 375-410.

Amihud, Y. (2002), Illiquidity and Stock Returns: Cross-Section and Time-Series Effects, Journal of Financial Markets 5, 31-56.

Bansal, R. and A. Yaron (2004), Risks for the Long Run: A Potential Resolution of Asset Pricing Puzzles, Journal of Finance 59, 1481-1509.

Brennan, M., T. Chordia, A. Subrahmanyam, and Q. Tong (2012), Sell-side Illiquidity and the Cross-Section of Expected Stock Returns, Journal of Financial Economics 105, 523-541.

Chordia, T. R. Roll, and A. Subrahmanyam (2000), Commonality in Liquidity, Journal of Financial Economics 56, 3-28.

Cochrane, J. (2008), Financial Markets and the Real Economy, in R. Mehra (2008) (Ed.), Handbook of the Equity Risk Premium, ch. 7. Noth Holland, 237-325.

Epstein, L. and E. Zin (1991), Substitution, Risk Aversion and the Temporal Behaviour of Asset Returns, Journal of Political Economy 99, 263-286.

Fama, E. and J. MacBeth (1973), Risk, Return and Equilibrium: Empirical Tests, Journal of Political Economy 71, 607-636.

Hansen, L., P. Heaton and N. Li (2008), Consumption Strikes Back? Measuring Long Run Risk, Journal of Political Economy 116, 260-302.

Hasbrouck, J. and D. Seppi (2001), Common Factors in Prices, Order Flows, and Liquidity, Journal of Financial Economics 59, 383-411.

He, H. and D. Modest (1995), Market Frictions and Consumption-Based Asset Pricing, Journal of Political Economy 103, 94-117.

Jagannathan, R. and Y. Wang (2007), Lazy Investors, Discretionary Consumption, and the Cross-Section of Stock Returns, Journal of Finance 62, 1623-1661.

Kamara, A., X. Lou, and R. Sadka (2008), The Divergence of Liquidity Commonality in the Cross-Section of Stocks, Journal of Financial Economics 89, 444-466.

Korajczyk, R. and R. Sadka (2008), Pricing the Commonality Across Alternative Measures of Liquidity, Journal of Financial Economics 87, 45-72. 
Kyle, A. (1985), Continuous Auctions and Insider Trading, Econometrica 53, 13151335.

Lewellen, J., S. Nagel and J. Shanken (2010), A Skeptical Appraisal of Asset-Pricing Tests, Journal of Financial Economics 96, 175-194.

Liu, W. (2006), A Liquidity Augmented Capital Asset Pricing Model, Journal of Financial Economics 82, 631-671.

Lustig, H., S. Van Nieuwerburgh (2005), Housing Collateral, Consumption Insurance, and Risk Premia: An Empirical Perspective, Journal of Finance 60, 1167-1219.

Parker, J. and C. Julliard (2005), Consumption Risk and the Cross-Section of Expected Returns, Journal of Political Economy, 113, 185-222.

Pastor, L. and R. Stambaugh (2003), Liquidity Risk and Expected Stock Returns, Journal of Political Economy 111, 642-685.

Sadka, R. (2006), Momentum and Post-Earnings Announcements Drift Anomalies: The Role of Liquidity Risk, Journal of Financial Economics 80, 309-349.

Watanabe, A. and M. Watanabe (2008), Time-Varying Liquidity Risk and the Cross Section of Stock Returns Review of Financial Studies 21, 2449-86. 


\section{Appendix A: Derivation of the Model}

\section{Recursive Utility with Aggregate Liquidity Constraints}

We assume recursive preferences, as in Epstein and Zin (1991)

$$
U_{t}=\left[(1-\beta) C_{t}^{1-\rho}+\beta\left(E_{t}\left(U_{t+1}^{1-\gamma}\right)\right)^{\frac{1-\rho}{1-\gamma}}\right]^{\frac{1}{1-\rho}}
$$

where $U_{t}$ denotes utility at time $t, C_{t}$ is the aggregate consumption at time $t, \beta$ is the subjective discount factor, $\gamma$ represents the coefficient of relative risk aversion, $\rho$ is the inverse of the elasticity of intertemporal substitution, and $E$ is the expectation operator.

Let's $p_{t}$ be the price of an investment asset at time $t$ and $X_{t+1}$ its future payoff; the representative agent solves the following consumption-investment maximization problem:

$$
\begin{aligned}
& \max _{z} U_{t} \\
& \text { s.t. } \\
& C_{t}=e_{t}-z p_{t} \\
& C_{t+1} / \phi\left(L_{t+1}\right)=e_{t+1}+z X_{t+1}
\end{aligned}
$$

where $z$ is the amount invested today in the asset, $e_{t}$ is the consumption endowment at time t, and $\phi\left(L_{t+1}\right)$ is a function of the aggregate illiquidity shocks that affects the investor's budget restriction. As mentioned in the main text, this function takes the value of 1 in normal times, a value lower than 1 if market-wide liquidity is high, and a value greater than 1 when an adverse illiquidity shock impact the economy. Hence, when a future adverse illiquidity shock is expected, $\phi\left(L_{t+1}\right)>1$, future consumption will be negatively affected. 
To get the maximum, $\frac{\partial U_{t}}{\partial z}=0$ must hold. Then, the first order condition is

$$
p_{t}=E_{t}\left[\beta\left(\frac{U_{t+1}}{E_{t}\left(U_{t+1}^{1-\gamma} \frac{1}{1-\gamma}\right.}\right)\left(\frac{C_{t+1}}{C_{t}}\right)^{-\rho} \phi\left(L_{t+1}\right) X_{t+1}\right]
$$

From the definition of the utility in equation (A1), the following equality holds

$$
\left(E_{t}\left(U_{t+1}^{1-\gamma}\right)\right)^{\frac{1}{1-\gamma}}=\left[\frac{1}{\beta}\left(U_{t}^{1-\rho}-(1-\beta) C_{t}^{1-\rho}\right)\right]^{\frac{1}{1-\rho}} .
$$

On the other hand, the marginal utility in terms of consumption is given by:

$$
\frac{\partial U_{t}}{\partial C_{t}}=U_{t}^{\rho}(1-\beta) C_{t}^{-\rho}
$$

Moreover, the utility is linearly homogeneous. Thus,

$$
\frac{U_{t}}{\partial U_{t} / \partial C_{t}}=W_{t}
$$

Combining equations (A5) and (A6), the intertemporal utility can be written as a function of the aggregate wealth:

$$
U_{t}=\left[W_{t}(1-\beta) C_{t}^{-\rho}\right]^{\frac{1}{1-\rho}}
$$

Using expressions (A4) and (A7) it is possible to show that

$$
\frac{U_{t+1}}{E_{t}\left(U_{t+1}^{1-\gamma}\right)^{\frac{1}{1-\gamma}}}=\left[\frac{W_{t+1}(1-\beta) C_{t+1}^{-\rho}}{\beta^{-1}\left(U_{t}^{1-\rho}-(1-\beta) C_{t}^{1-\rho}\right)}\right]^{\frac{1}{1-\rho}}=\beta^{\frac{1}{1-\rho}}\left(\frac{W_{t+1}}{W_{t}-C_{t}}\right)^{\frac{1}{1-\rho}}\left(\frac{C_{t+1}}{C_{t}}\right)^{\frac{-\rho}{1-\rho}}
$$

Introducing equation (A8) into (A3): 


$$
p_{t}=E_{t}\left[\beta^{\frac{1-\gamma}{1-\rho}}\left(\frac{W_{t+1}}{W_{t}-C_{t}}\right)^{\frac{\rho-\gamma}{1-\rho}}\left(\frac{C_{t+1}}{C_{t}}\right)^{\frac{-\rho(1-\gamma)}{1-\rho}} \phi\left(L_{t+1}\right) X_{t+1}\right] .
$$

Finally, under our specification, the intertemporal budget constraint for the aggregate wealth is

$$
\frac{W_{t+1}}{\phi\left(L_{t+1}\right)}=\left(W_{t}-C_{t}\right) R_{W t+1}
$$

where $R_{W t+1}$ is defined as the return on the aggregate wealth.

Combining equations (A9) and (A10) and defining $\kappa=\frac{1-\gamma}{1-\rho}$, we obtain

$$
p_{t}=E_{t}\left[\beta^{\kappa} R_{W t+1}^{\kappa-1}\left(\frac{C_{t+1}}{C_{t}}\right)^{-\rho \kappa} \phi\left(L_{t+1}\right)^{\kappa} X_{t+1}\right] .
$$

This implies that the liquidity-adjusted SDF with recursive preferences is given by

$$
M_{L A R, t+1}=\beta^{\kappa} R_{W t+1}^{\kappa-1}\left(\frac{C_{t+1}}{C_{t}}\right)^{-\rho \kappa} \phi\left(L_{t+1}\right)^{\kappa} .
$$

\section{Recursive Utility with Aggregate Liquidity Constraints under Ultimate}

\section{Consumption Risk}

Equation (A3) can be rewritten in terms of the asset returns in the following form

$$
C_{t}^{-\rho}=E_{t}\left[\beta\left(\frac{U_{t+1}}{E_{t}\left(U_{t+1}^{1-\gamma}\right)^{\frac{1}{1-\gamma}}}\right)^{\rho-\gamma} C_{t+1}^{-\rho} \phi\left(L_{t+1}\right) R_{t+1}\right] .
$$


Now, we assume that a risk free asset exists, being $R_{f}$ its return. Applying (A13) to the risk free rate and expanding forward by substituting the future consumption, we obtain

$$
C_{t}^{-\rho}=E_{t}\left[\beta^{S} \prod_{\tau=1}^{S}\left(\frac{U_{t+\tau}}{E_{t+\tau-1}\left(U_{t+\tau}^{1-\gamma}\right)^{\frac{1}{1-\gamma}}}\right)^{\rho-\gamma} C_{t+S}^{-\rho} \phi\left(L_{t+1, t+S}\right) R_{f t, t+S}\right],
$$

where the subscripts in the form $(t, t+S)$ indicate the cumulative value of the variable from period $t$ to period $t+S$.

Applying equation (A14) to $C_{t+1}^{-\rho}$ and introducing it in (A13)

$$
C_{t}^{-\rho}=E_{t}\left[\beta^{S+1} \coprod_{\tau=0}^{S}\left(\frac{U_{t+\tau+1}}{E_{t+\tau}\left(U_{t+\tau+1}^{1-\gamma}\right)^{\frac{1}{1-\gamma}}}\right)^{\rho-\gamma} C_{t+1+S}^{-\rho} \phi\left(L_{t+1, t+1+S}\right) R_{f t+1, t+1+S} R_{t+1}\right]
$$

Finally, and as before, equations (A8) and (A10) are combined with (A15) and after some algebra the Euler condition takes the following form

$$
1=E_{t}\left[\beta^{(S+1) \kappa}\left(\frac{C_{t+1+S}}{C_{t}}\right)^{-\rho \kappa} R_{W t+1, t+1+S}^{\kappa-1} \phi\left(L_{t+1, t+1+S}\right)^{\kappa} R_{f t+1, t+1+S} R_{t+1}\right] .
$$

Therefore, the SDF under this specification is

$$
M_{L A R, t+1}^{S}=\left[\beta^{(S+1)}\left(\frac{C_{t+1+S}}{C_{t}}\right)^{-\rho} \phi\left(L_{t+1, t+1+S}\right)\right]^{\kappa} R_{W t+1, t+1+S}^{\kappa-1} R_{f t+1, t+1+S} .
$$

\section{APPENDIX B: The linear factor model approximation}

Now we obtain the beta (linear) version of the models analyzed in the paper. We do it for the most general case; this is, the recursive preferences with illiquidity shocks and 
ultimate consumption risk. The rest of the models are just special cases of our general specification.

The non-linear model for pricing an asset $j$ is given by

$$
E_{t}\left[M_{L A R, t+1}^{S} R_{j t+1}\right]=1 .
$$

Using the definition of the covariance, equation (B1) can be written as

$$
E_{t}\left(R_{j t+1}-R_{f t+1}\right)=-\frac{\operatorname{Cov}_{t}\left(M_{L A R, t+1}^{S}, R_{j t+1}\right)}{E_{t}\left(M_{L A R, t+1}^{S}\right)}
$$

The SDF based on recursive preferences with illiquidity shocks in the intertemporal budget constrain and ultimate risk is given by:

$$
M_{L A R, t+1}^{S}=\left[\beta^{S+1}\left(\frac{C_{t+1+S}}{C_{t}}\right)^{-\rho} \phi\left(L_{t+1, t+1+S}\right)\right]^{\kappa} R_{W t+1, t+1+S}^{K-1} R_{f t+1, t+1+S} .
$$

Taking logs in the SDF, we get

$$
m_{L A R, t+1}^{S}=\kappa(S+1) \log (\beta)-\kappa \rho \Delta c_{t, t+1+S}+\kappa \log \left(\phi\left(L_{t+1, t+1+S}\right)\right)+(\kappa-1) r_{W t+1, t+1+S}+r_{f t+1, t+1+S},
$$

where lowercase letters denote the logs of uppercase letters.

Assuming that the risk free rate is approximately constant over time, the covariance between the linear SDF in (B4) and the return on asset $j$ is given by 
$\operatorname{Cov}_{t}\left(m_{L A R, t+1}^{S}, R_{j t+1}\right)=$
$-\kappa \rho \operatorname{Cov}_{t}\left(\Delta c_{t, t+1+S}, R_{j t+1}\right)+\kappa \operatorname{Cov}_{t}\left(\log \left(\phi\left(L_{t+1, t+1+S}\right)\right), R_{j t+1}\right)+(\kappa-1) \operatorname{Cov}_{t}\left(r_{W t+1, t+1+S}, R_{j t+1}\right)$

Introducing (B5) in (B2) and operating, the beta version of the model is

$$
E_{t}\left(R_{j t+1}-R_{f t+1}\right) \cong \gamma_{1} \beta_{j c t}+\gamma_{2} \beta_{j \phi t}+\gamma_{3} \beta_{j W t}
$$

where the risk premium associated to each beta is given by $\gamma_{1}=\frac{\kappa \rho \operatorname{Var}_{t}\left(\Delta c_{t, t+1+S}\right)}{E_{t}\left(M_{L A R, t+1}^{S}\right)}$, $\gamma_{2}=\frac{-\kappa \operatorname{Var}_{t}\left(\log \left(\phi\left(L_{t+1, t+1+S}\right)\right)\right)}{E_{t}\left(M_{L A R, t+1}^{S}\right)}$, and $\gamma_{3}=\frac{(1-\kappa) \operatorname{Var}_{t}\left(r_{W t+1, t+1+S}\right)}{E_{t}\left(M_{L A R, t+1}^{S}\right)}$, respectively, and the three risk factors are determined as $\beta_{j c t}=\frac{\operatorname{Cov}_{t}\left(\Delta c_{t, t+1+S}, R_{j t+1}\right)}{\operatorname{Var}_{t}\left(\Delta c_{t, t+1+S}\right)}$, $\beta_{j \phi t}=\frac{\operatorname{Cov}_{t}\left(\log \left(\phi\left(L_{t+1, t+1+S}\right)\right), R_{j t+1}\right)}{\operatorname{Var}_{t}\left(\log \left(\phi\left(L_{t+1, t+1+S}\right)\right)\right)}$, and $\beta_{j W t}=\frac{\operatorname{Cov}_{t}\left(r_{W t+1, t+1+S}, R_{j t+1}\right)}{\operatorname{Var}_{t}\left(r_{W t+1, t+1+S}\right)}$ 
Table 1.a

Descriptive Statistics: 25Fama and French Portfolios (Amihud Illiquidity Measure)

\begin{tabular}{|rccccc|c|}
\hline \multicolumn{7}{c|}{ PANEL A: Mean return and Standard deviation } \\
\hline & Low & 2 & 3 & 4 & High & Mean \\
\hline Small & 2.400 & 3.961 & 4.075 & 4.661 & 5.126 & 4.045 \\
& $(16.48)$ & $(13.95)$ & $(12.21)$ & $(11.69)$ & $(12.78)$ & $(13.09)$ \\
2 & 2.774 & 3.583 & 4.243 & 4.432 & 4.616 & 3.930 \\
& $(14.46)$ & $(12.09)$ & $(10.73)$ & $(10.41)$ & $(11.36)$ & $(11.38)$ \\
3 & 2.831 & 3.713 & 3.716 & 4.046 & 4.590 & 3.779 \\
& $(13.08)$ & $(10.73)$ & $(9.59)$ & $(9.51)$ & $(10.56)$ & $(10.15)$ \\
& 3.109 & 3.059 & 3.596 & 4.022 & 4.075 & 3.572 \\
& $(11.76)$ & $(9.88)$ & $(9.06)$ & $(9.05)$ & $(10.18)$ & $(9.42)$ \\
Big & 2.689 & 2.918 & 2.799 & 3.097 & 3.265 & 2.954 \\
& $(9.04)$ & $(8.17)$ & $(7.37)$ & $(7.38)$ & $(8.42)$ & $(7.41)$ \\
\hline Mean & 2.761 & 3.447 & 3.686 & 4.052 & 4.334 & \\
& $(12.46)$ & $(10.47)$ & $(9.28)$ & $(9.14)$ & $(10.09)$ & \\
\hline
\end{tabular}

PANEL B: Return-based illiquidity betas from the time series regression:

\begin{tabular}{|cccccc|c|}
\hline \multicolumn{7}{|c|}{ PANEL B: Return-based illiquidity betas from the time series regression: } \\
\hline \multicolumn{7}{c}{$R_{j t}=\alpha_{j}+\beta_{j} \phi\left(L_{t}\right)+u_{j t}$} \\
\hline Small & Low & 2 & 3 & 4 & High & Mean \\
& -1.509 & -1.300 & -1.116 & -1.104 & -1.191 & -1.244 \\
& $(-7.95)$ & $(-8.14)$ & $(-7.93)$ & $(-8.29)$ & $(-8.14)$ & $(-8.36)$ \\
& -1.373 & -1.178 & -1.054 & -1.004 & -1.042 & -1.130 \\
& $(-8.35)$ & $(-8.66)$ & $(-8.77)$ & $(-8.54)$ & $(-7.96)$ & $(-8.91)$ \\
& -1.292 & -1.070 & -0.883 & -0.880 & -0.901 & -1.005 \\
& $(-8.83)$ & $(-8.95)$ & $(-8.01)$ & $(-8.07)$ & $(-7.23)$ & $(-8.87)$ \\
& -1.152 & -0.931 & -0.812 & -0.763 & -0.866 & -0.905 \\
& $(-8.73)$ & $(-8.26)$ & $(-7.72)$ & $(-7.12)$ & $(-7.21)$ & $(-8.48)$ \\
& -0.800 & -0.692 & -0.548 & -0.574 & -0.640 & -0.651 \\
& $(-7.59)$ & $(-7.17)$ & $(-6.10)$ & $(-6.44)$ & $(-6.26)$ & $(-7.52)$ \\
\hline Big & -1.225 & -1.034 & -0.883 & -0.865 & -0.928 & \\
& $(-8.78)$ & $(-8.84)$ & $(-8.38)$ & $(-8.31)$ & $(-8.00)$ & \\
\hline
\end{tabular}

PANEL C: Return-based illiquidity betas from the time series regression:

\begin{tabular}{|rccccc|c|}
\multicolumn{7}{c|}{ PANEL C: Return-based illiquidity betas from the time series regression: } \\
\hline \multicolumn{7}{c}{$R_{j t}=\alpha_{j}+\beta_{j \phi} \phi\left(L_{t}\right)+\beta_{j W} R_{W t}+\beta_{j c} \Delta C_{t}+u_{j t}$} \\
\hline Small & Low & 2 & 3 & 4 & High & Mean \\
& -0.218 & -0.209 & -0.188 & -0.262 & -0.310 & -0.237 \\
2 & $(-1.50)$ & $(-1.70)$ & $(-1.68)$ & $(-2.35)$ & $(-2.40)$ & $(-2.07)$ \\
& -0.176 & -0.223 & -0.204 & -0.221 & -0.201 & -0.205 \\
3 & $(-1.65)$ & $(-2.37)$ & $(-2.42)$ & $(-2.44)$ & $(-1.86)$ & $(-2.48)$ \\
& -0.199 & -0.175 & -0.096 & -0.146 & -0.116 & -0.146 \\
& $(-2.33)$ & $(-2.50)$ & $(-1.29)$ & $(-1.76)$ & $(-1.11)$ & $(-2.26)$ \\
& -0.140 & -0.081 & -0.043 & 0.007 & -0.060 & -0.064 \\
& $(-1.98)$ & $(-1.26)$ & $(-0.66)$ & $(0.10)$ & $(-0.65)$ & $(-1.23)$ \\
& 0.037 & 0.053 & 0.118 & 0.053 & 0.027 & 0.057 \\
& $(0.74)$ & $(1.13)$ & $(2.05)$ & $(0.86)$ & $(0.33)$ & $(1.75)$ \\
\hline Big & -0.139 & -0.127 & -0.083 & -0.114 & -0.132 & \\
\hline
\end{tabular}

The sample period goes from 1963:II to 2008:I. In Panel A, mean returns and standard deviations (in parentheses) are in percentages. In Panels B and C, numbers are the sensitivities of returns to the illiquidity factor and the correspondent $t$-statistics (in parentheses). In the three panels, last column refers to the average portfolio of the five book-to-market groups for each size portfolio and the last row refers to the average portfolio of the five size groups for each book-to-market portfolio. $R_{j t}$ denotes the gross return on portfolio $j$ at time $t, \phi\left(L_{t}\right)$ is the illiquidity function that employs the Amihud ratio, $R_{W t}$ is the gross return on aggregate wealth, and $\Delta C_{t}$ is the non durable consumption growth rate. 
Table 1.b

Descriptive Statistics: 17 Industry Portfolios (Amihud Illiquidity Measure)

\begin{tabular}{|l|c|c|rl|rl|}
\hline & $\begin{array}{c}\text { Mean } \\
\text { Return }\end{array}$ & $\begin{array}{c}\text { Standard } \\
\text { Deviation }\end{array}$ & \multicolumn{2}{|c|}{$\begin{array}{c}\text { Illiquidity beta } \\
\text { Simple regression }\end{array}$} & \multicolumn{2}{|c|}{$\begin{array}{c}\text { Illiquidity beta } \\
\text { Multiple regression }\end{array}$} \\
\hline Durables & 2.430 & 10.244 & -0.968 & $(-8.30)$ & -0.199 & $(-2.22)$ \\
Utilities & 2.639 & 7.485 & -0.308 & $(-3.15)$ & 0.210 & $(2.28)$ \\
Cars & 2.688 & 11.365 & -0.795 & $(-5.66)$ & 0.076 & $(0.63)$ \\
Other & 2.697 & 9.275 & -0.876 & $(-8.29)$ & -0.024 & $(-0.55)$ \\
Steel & 2.704 & 11.692 & -0.824 & $(-5.72)$ & 0.026 & $(0.20)$ \\
Chemicals & 2.852 & 9.084 & -0.736 & $(-6.77)$ & -0.033 & $(-0.39)$ \\
Fab. Products & 3.037 & 9.775 & -0.884 & $(-7.81)$ & -0.155 & $(-1.75)$ \\
Construction & 3.079 & 11.540 & -1.106 & $(-8.46)$ & -0.165 & $(-1.96)$ \\
Machinery & 3.154 & 11.970 & -1.053 & $(-7.53)$ & -0.021 & $(-0.23)$ \\
Transport & 3.183 & 10.651 & -0.929 & $(-7.45)$ & -0.083 & $(-0.88)$ \\
Finance & 3.205 & 10.027 & -0.873 & $(-7.43)$ & -0.026 & $(-0.34)$ \\
Retail & 3.288 & 10.963 & -1.014 & $(-8.06)$ & -0.162 & $(-1.72)$ \\
Cloths & 3.308 & 12.490 & -1.241 & $(-8.90)$ & -0.406 & $(-3.37)$ \\
Consumption & 3.387 & 8.850 & -0.601 & $(-5.47)$ & 0.036 & $(0.37)$ \\
Food & 3.462 & 8.684 & -0.746 & $(-7.30)$ & -0.152 & $(-1.74)$ \\
Oil & 3.478 & 8.487 & -0.363 & $(-3.28)$ & 0.195 & $(1.77)$ \\
Mines & 3.559 & 11.882 & -0.649 & $(-4.28)$ & 0.059 & $(0.38)$ \\
\hline
\end{tabular}

The sample period goes from 1963:II to 2008:I. Mean returns and standard deviations are in percentages. Simple regression refers to the equation on top of Panel B of Table 1.a, and multiple regressions refer to the equation on top of Panel $\mathrm{C}$ of Table 1.a. These two last columns show illiquidity sensitivities and the corresponding $t$-statistics (in parentheses). 
Table 2

Market-Wide Illiquidity and the Fama-French Factors (Amihud Illiquidity Measure) 1963:II-2008:I

\begin{tabular}{|cccc|}
\hline \multicolumn{4}{|c|}{$\phi\left(L_{t}\right)=\delta_{0}+\delta_{W} R_{W t}^{e}+\delta_{S M B} S M B_{t}+\delta_{\text {HLL }} H M L_{t}+u_{t}$} \\
\hline$\delta_{W}$ & $\delta_{S M B}$ & $\delta_{H M L}$ & $R_{a d j}^{2}$ \\
\hline-0.308 & -0.199 & -0.017 & 31.85 \\
$(-5.95)$ & $(-2.94)$ & $(-0.25)$ & 29.24 \\
-0.367 & & & 16.67 \\
$(-8.66)$ & -0.402 & & 4.32 \\
& $(-6.07)$ & 0.212 & 18.61 \\
& & $(3.01)$ & \\
& -0.377 & 0.151 & $(2.29)$ \\
\hline
\end{tabular}

Table 2 displays the estimated coefficients of the regression on top of the table. $\phi\left(L_{t}\right)$ is an illiquidity function that employs the Amihud ratio, $R_{W t}^{e}$ is the excess return on aggregate wealth, $S M B_{t}$ is the Fama-French size factor, and $H M L_{t}$ is the Fama-French book-to-market factor. The results refer to the sample period 1963:II to 2008:I and $t$-statistics are in parentheses. 
Table 3.a

Fama-MacBeth Estimation with Rolling Betas

CCAPM with Market-Wide Illiquidity Shocks (Amihud Illiquidity Measure)

\begin{tabular}{|c|c|c|c|c|c|c|c|}
\hline \multicolumn{8}{|c|}{ PANEL A: 25 Fama and French Portfolios } \\
\hline \multicolumn{4}{|c|}{$S=0$} & \multicolumn{4}{|c|}{$S=11$} \\
\hline$\gamma_{0}$ & $\gamma_{2}$ & $\gamma_{3}$ & $R_{a d j}^{2}$ & $\gamma_{0}$ & $\gamma_{2}$ & $\gamma_{3}$ & $R_{a d j}^{2}$ \\
\hline $\begin{array}{c}0.0279 \\
(3.96)\end{array}$ & $\begin{array}{c}-0.0013 \\
(-1.30)\end{array}$ & & 32.54 & $\begin{array}{c}0.0206 \\
(2.57)\end{array}$ & $\begin{array}{c}-0.0007 \\
(-0.13)\end{array}$ & & 32.46 \\
\hline $\begin{array}{c}0.0220 \\
(3.22)\end{array}$ & $\begin{array}{c}-0.0033 \\
(-3.24)\end{array}$ & $\begin{array}{c}-0.0025 \\
(-0.32)\end{array}$ & 56.80 & $\begin{array}{c}0.0176 \\
(2.42)\end{array}$ & $\begin{array}{c}0.0018 \\
(0.31)\end{array}$ & $\begin{array}{c}-0.0368 \\
(-1.68)\end{array}$ & 56.08 \\
\hline \multicolumn{8}{|c|}{ PANEL B: 25 Fama and French Portfolios and 17 Industry Portfolios } \\
\hline \multicolumn{4}{|c|}{$S=0$} & \multicolumn{4}{|c|}{$S=11$} \\
\hline$\gamma_{0}$ & $\gamma_{2}$ & $\gamma_{3}$ & $R_{a d j}^{2}$ & $\gamma_{0}$ & $\gamma_{2}$ & $\gamma_{3}$ & $R_{a d j}^{2}$ \\
\hline $\begin{array}{c}0.0255 \\
(4.04)\end{array}$ & $\begin{array}{l}-0.001 \\
(-1.74)\end{array}$ & & 20.69 & $\begin{array}{c}0.0217 \\
(3.10)\end{array}$ & $\begin{array}{c}-0.0035 \\
(-0.83)\end{array}$ & & 22.87 \\
\hline $\begin{array}{c}0.0194 \\
(3.51)\end{array}$ & $\begin{array}{c}-0.0018 \\
(-2.66)\end{array}$ & $\begin{array}{c}-0.0016 \\
(-0.24)\end{array}$ & 38.58 & $\begin{array}{c}0.0183 \\
(2.85)\end{array}$ & $\begin{array}{c}-0.0024 \\
(-0.53)\end{array}$ & $\begin{array}{c}-0.0243 \\
(-1.51)\end{array}$ & 37.52 \\
\hline
\end{tabular}

Table 3.a displays estimates of the risk premia from different versions of the following cross-sectional regression from 1971:I to 2008:I,

$$
R_{j t}-R_{f t}=\gamma_{0}+\gamma_{1} \beta_{j c t}+\gamma_{2} \beta_{j \phi t}+e_{j t}
$$

which is consistent with the power utility function and market-wide illiquidity shocks. $\beta_{j c}$ and $\beta_{j \phi}$ are the sensitivities of the return on asset $j$ to changes into two risk factors: non-durable consumption growth and aggregate illiquidity respectively, and $t$-statistics are in parentheses. Betas are estimated with a rolling window of 32 quarters previous to each cross-sectional regression. $S=0$ means that the risk factors are computed from $t$ to $t+1$. $S=11$ means that the risk factors are computed from the cumulative returns from $t$ to $t+12 . R_{a d j}^{2}$ is the adjusted determination coefficient, reported as percentage, and computed using the sum of the total sums and the sum of the residual sums from each cross-sectional regression. 
Table 3.b

Fama-MacBeth Estimation with Rolling Betas

Recursive Preferences with Market-Wide Illiquidity Shocks

(Amihud Illiquidity Measure)

\begin{tabular}{|c|c|c|c|c|c|c|c|c|c|}
\hline \multicolumn{10}{|c|}{ PANEL A: 25 Fama and French Portfolios } \\
\hline \multicolumn{5}{|c|}{$S=0$} & \multicolumn{5}{|c|}{$S=11$} \\
\hline$\gamma_{0}$ & $\gamma_{1}$ & $\gamma_{2}$ & $\gamma_{3}$ & $R_{a d j}^{2}$ & $\gamma_{0}$ & $\gamma_{1}$ & $\gamma_{2}$ & $\gamma_{3}$ & $R_{a d j}^{2}$ \\
\hline $\begin{array}{c}0.0307 \\
(3.59)\end{array}$ & $\begin{array}{c}-0.0028 \\
(-3.71)\end{array}$ & & $\begin{array}{c}-0.0132 \\
(-1.32)\end{array}$ & 56.70 & $\begin{array}{c}0.01623 \\
(2.31)\end{array}$ & $\begin{array}{c}-0.0007 \\
(-0.13)\end{array}$ & & $\begin{array}{c}0.0658 \\
(1.22)\end{array}$ & 50.23 \\
\hline $\begin{array}{c}0.0300 \\
(3.48)\end{array}$ & $\begin{array}{c}-0.0025 \\
(-2.73)\end{array}$ & $\begin{array}{c}-0.0043 \\
(-0.51)\end{array}$ & $\begin{array}{c}-0.0133 \\
(-1.30)\end{array}$ & 68.60 & $\begin{array}{c}0.0192 \\
(2.97)\end{array}$ & $\begin{array}{c}0.0013 \\
(0.26)\end{array}$ & $\begin{array}{c}-0.0406 \\
(-1.99)\end{array}$ & $\begin{array}{c}0.0380 \\
(0.84)\end{array}$ & 65.46 \\
\hline \multicolumn{10}{|c|}{ PANEL B: 25 Fama and French Portfolios and 17 Industry Portfolios } \\
\hline \multicolumn{5}{|c|}{$S=0$} & \multicolumn{5}{|c|}{$S=11$} \\
\hline$\gamma_{0}$ & $\gamma_{1}$ & $\gamma_{2}$ & $\gamma_{3}$ & $R_{a d j}^{2}$ & $\gamma_{0}$ & $\gamma_{1}$ & $\gamma_{2}$ & $\gamma_{3}$ & $R_{a d j}^{2}$ \\
\hline $\begin{array}{c}0.0212 \\
(3.42)\end{array}$ & $\begin{array}{c}-0.0018 \\
(-2.97)\end{array}$ & & $\begin{array}{c}-0.0037 \\
(-0.43)\end{array}$ & 38.72 & $\begin{array}{c}0.0171 \\
(2.72)\end{array}$ & $\begin{array}{l}-0.0051 \\
(-1.16)\end{array}$ & & $\begin{array}{c}0.0337 \\
(0.79)\end{array}$ & 36.91 \\
\hline $\begin{array}{c}0.0195 \\
(3.04)\end{array}$ & $\begin{array}{c}-0.0016 \\
(-2.42) \\
\end{array}$ & $\begin{array}{c}0.0042 \\
(0.52)\end{array}$ & $\begin{array}{c}-0.0018 \\
(-0.20) \\
\end{array}$ & 49.04 & $\begin{array}{c}0.0176 \\
(2.85) \\
\end{array}$ & $\begin{array}{c}-0.0042 \\
(-0.95)\end{array}$ & $\begin{array}{c}-0.0235 \\
(-1.50) \\
\end{array}$ & $\begin{array}{c}0.0241 \\
(0.58)\end{array}$ & 47.06 \\
\hline
\end{tabular}

Table 3.b displays estimates of the risk premia from different versions of the following cross-sectional regression from 1971:I to 2008:I,

$$
R_{j t}-R_{f t}=\gamma_{0}+\gamma_{1} \beta_{j c t}+\gamma_{2} \beta_{j \phi t}+\gamma_{3} \beta_{j W t}+e_{j t}
$$

which is consistent with the recursive utility function and market-wide illiquidity shocks. $\beta_{j c}, \beta_{j \phi}$ and $\beta_{j w}$ are the sensitivities of the return on asset $j$ to changes in non-durable consumption growth, aggregate illiquidity, and return on aggregate wealth respectively, and $t$-statistics are in parentheses. Betas are estimated with a rolling window of 32 quarters previous to each cross-sectional regression. $S=0$ means that the risk factors are computed from $t$ to $t+1 . S=11$ means that the risk factors are computed from the cumulative returns from $t$ to $t+12$. $R_{a d j}^{2}$ is the adjusted determination coefficient, reported as percentage, and computed using the sum of the total sums and the sum of the residual sums from each cross-sectional regression. 
Table 4

Fama-MacBeth Estimation with Rolling Betas

Recursive Preferences with Market-Wide Illiquidity Shocks with Alternative Portfolio

Sorting Procedures (Amihud Illiquidity Measure)

\begin{tabular}{|c|c|c|c|c|c|c|c|c|c|}
\hline \multicolumn{10}{|c|}{ PANEL A: 25 Fama and French Portfolios and 10 Dividend Yield Portfolios } \\
\hline \multicolumn{5}{|c|}{$S=0$} & \multicolumn{5}{|c|}{$S=11$} \\
\hline$\gamma_{0}$ & $\gamma_{1}$ & $\gamma_{2}$ & $\gamma_{3}$ & $R_{a d j}^{2}$ & $\gamma_{0}$ & $\gamma_{1}$ & $\gamma_{2}$ & $\gamma_{3}$ & $R_{a d j}^{2}$ \\
\hline $\begin{array}{c}0.0263 \\
(3.54)\end{array}$ & $\begin{array}{c}-0.0025 \\
(-3.26 ; 8)\end{array}$ & & $\begin{array}{c}-0.0094 \\
(-1.01)\end{array}$ & 54.33 & $\begin{array}{c}0.01705 \\
(2.54)\end{array}$ & $\begin{array}{c}-0.0030 \\
(-0.64)\end{array}$ & & $\begin{array}{c}0.0530 \\
(1.04)\end{array}$ & 47.73 \\
\hline $\begin{array}{c}0.0240 \\
(3.21)\end{array}$ & $\begin{array}{c}-0.0022 \\
(-2.61)\end{array}$ & $\begin{array}{c}-0.0004 \\
(-0.05)\end{array}$ & $\begin{array}{c}-0.0074 \\
(-0.78)\end{array}$ & 64.89 & $\begin{array}{c}0.0186 \\
(3.01)\end{array}$ & $\begin{array}{c}-0.0013 \\
(-0.30)\end{array}$ & $\begin{array}{c}-0.0351 \\
(-1.85)\end{array}$ & $\begin{array}{c}0.0343 \\
(0.78)\end{array}$ & 61.29 \\
\hline \multicolumn{10}{|c|}{ PANEL B: 25 Fama and French Portfolios and 10 Momentum Portfolios } \\
\hline \multicolumn{5}{|c|}{$S=0$} & \multicolumn{5}{|c|}{$S=11$} \\
\hline$\gamma_{0}$ & $\gamma_{1}$ & $\gamma_{2}$ & $\gamma_{3}$ & $R_{a d j}^{2}$ & $\gamma_{0}$ & $\gamma_{1}$ & $\gamma_{2}$ & $\gamma_{3}$ & $R_{a d j}^{2}$ \\
\hline $\begin{array}{c}0.0289 \\
(3.53)\end{array}$ & $\begin{array}{c}-0.0004 \\
(-0.59)\end{array}$ & & $\begin{array}{c}-0.0106 \\
(-1.02)\end{array}$ & 48.36 & $\begin{array}{l}0.0177 \\
(2.68)\end{array}$ & $\begin{array}{c}-0.0058 \\
(-1.21)\end{array}$ & & $\begin{array}{c}0.0180 \\
(0.43)\end{array}$ & 42.69 \\
\hline $\begin{array}{c}0.0290 \\
(3.73) \\
\end{array}$ & $\begin{array}{c}-0.0007 \\
(-0.81) \\
\end{array}$ & $\begin{array}{r}-0.0047 \\
(-0.50) \\
\end{array}$ & $\begin{array}{c}-0.0116 \\
(-1.13) \\
\end{array}$ & 60.08 & $\begin{array}{c}0.0256 \\
(4.11)\end{array}$ & $\begin{array}{c}-0.0040 \\
(-0.86) \\
\end{array}$ & $\begin{array}{c}-0.0527 \\
(-2.84) \\
\end{array}$ & $\begin{array}{c}0.0054 \\
(0.12) \\
\end{array}$ & 56.91 \\
\hline
\end{tabular}

Table 4 displays estimates of the risk premia from different versions of the following cross-sectional regression from 1971:I to 2008:I,

$$
R_{j t}-R_{f t}=\gamma_{0}+\gamma_{1} \beta_{j c t}+\gamma_{2} \beta_{j \phi t}+\gamma_{3} \beta_{j W t}+e_{j t}
$$

which is consistent with the recursive utility function and market-wide illiquidity shocks. $\beta_{j c}, \beta_{j \phi}$ and $\beta_{j w}$ are the sensitivities of the return on asset $j$ to changes in non-durable consumption growth, aggregate illiquidity, and return on aggregate wealth respectively, and $t$-statistics are in parentheses. Betas are estimated with a rolling window of 32 quarters previous to each cross-sectional regression. $S=0$ means that the risk factors are computed from $t$ to $t+1 . S=11$ means that the risk factors are computed from the cumulative returns from $t$ to $t+12$. $R_{a d j}^{2}$ is the adjusted determination coefficient, reported as percentage, and computed using the sum of the total sums and the sum of the residual sums from each cross-sectional regression. 
Table 5

Fama-MacBeth Estimation with Rolling Betas: Risk Premia Seasonality Recursive Preference and Illiquidity Shocks 25 Fama and French Portfolios and 17 Industry Portfolios (Amihud Illiquidity Measure)

\begin{tabular}{|c|c|c|c|c|c|c|c|}
\hline \multicolumn{4}{|c|}{ Risk premia first quarter: $S=0$} & \multicolumn{4}{|c|}{ Risk premia first quarter: $S=11$} \\
\hline$\hat{a}$ for $\gamma_{0}$ & $\hat{a}$ for $\gamma_{1}$ & $\hat{a}$ for $\gamma_{2}$ & $\hat{a}$ for $\gamma_{3}$ & $\hat{a}$ for $\gamma_{0}$ & $\hat{a}$ for $\gamma_{1}$ & $\hat{a}$ for $\gamma_{2}$ & $\hat{a}$ for $\gamma_{3}$ \\
\hline $\begin{array}{c}0.0189 \\
(1.49)\end{array}$ & $\begin{array}{c}-0.0020 \\
(-1.51)\end{array}$ & $\begin{array}{c}-0.0316 \\
(-2.02)\end{array}$ & $\begin{array}{c}0.0117 \\
(0.67)\end{array}$ & $\begin{array}{c}0.0365 \\
(3.00)\end{array}$ & $\begin{array}{c}0.0094 \\
(1.08)\end{array}$ & $\begin{array}{c}-0.0938 \\
(-3.09)\end{array}$ & $\begin{array}{c}0.0175 \\
(0.21)\end{array}$ \\
\hline \multicolumn{4}{|c|}{$\begin{array}{l}\text { Difference between risk premia during the rest of } \\
\text { the year and the first quarter: } S=0\end{array}$} & \multicolumn{4}{|c|}{$\begin{array}{l}\text { Difference between risk premia during the rest of } \\
\text { the year and the first quarter: } S=11\end{array}$} \\
\hline$\hat{b}$ for $\gamma_{0}$ & $\hat{b}$ for $\gamma_{1}$ & $\hat{b}$ for $\gamma_{2}$ & $\hat{b}$ for $\gamma_{3}$ & $\hat{b}$ for $\gamma_{0}$ & $\hat{b}$ for $\gamma_{1}$ & $\hat{b}$ for $\gamma_{2}$ & $\hat{b}$ for $\gamma_{3}$ \\
\hline 0.0008 & 0.0005 & 0.0481 & -0.0180 & -0.0215 & -0.0183 & 0.0943 & 0.0089 \\
\hline$(0.05)$ & $(0.34)$ & $(2.66)$ & $(-0.89)$ & $(-1.80)$ & $(-1.81)$ & $(2.68)$ & $(0.09)$ \\
\hline
\end{tabular}

Table 5 displays the risk premia estimates from the first quarter of the full sample period, and for the difference between the rest of the year and the first quarter from 1971:I to 2008:I. In particular, we run the following regression under recursive preferences with illiquidity shocks:

$$
\hat{\gamma}_{i t}=a+b D_{R Y t}+u_{i t}, i=1,2,3 \text {, and } 4
$$

where $\hat{\gamma}_{i t}$ are the time-series of the estimated risk premia corresponding to the second row of the Panel B of Table 3.b, and $D_{R Y t}$ is a dummy variable which is equal to one for quarters 2,3 and 4 , and zero otherwise. Then, the estimated intercept is the average risk premia for the first quarter, while the estimated slopes represent the difference between the risk premia during the rest of the year and the first quarter. We report the results for both the contemporaneous $(S=0)$ and ultimate risk specifications $(S=11)$ of the SDFs. $t$-statistic in parentheses. 
Figure 1

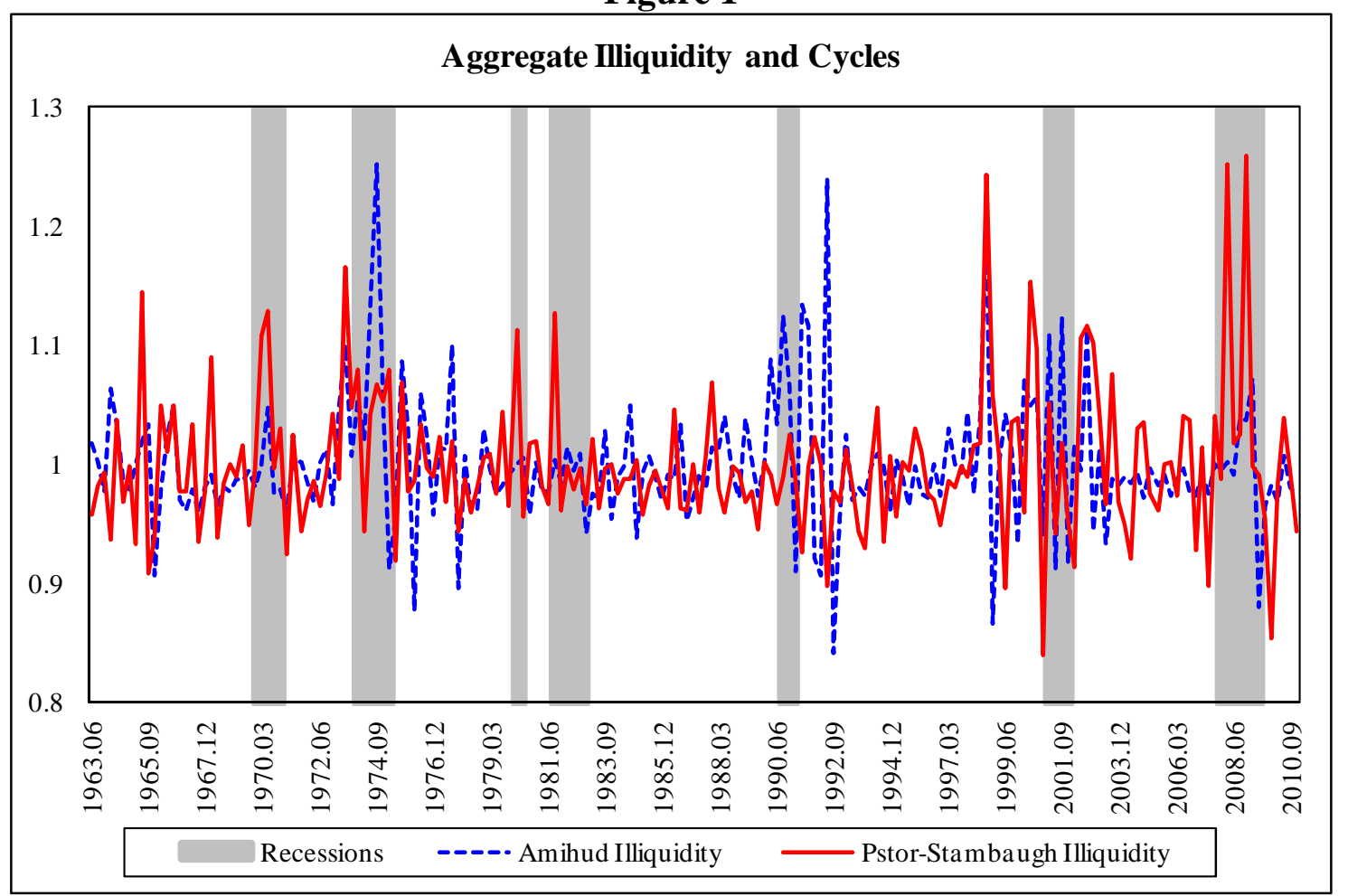


Figure 2

Illiquidity shocks, SDF and Cycles
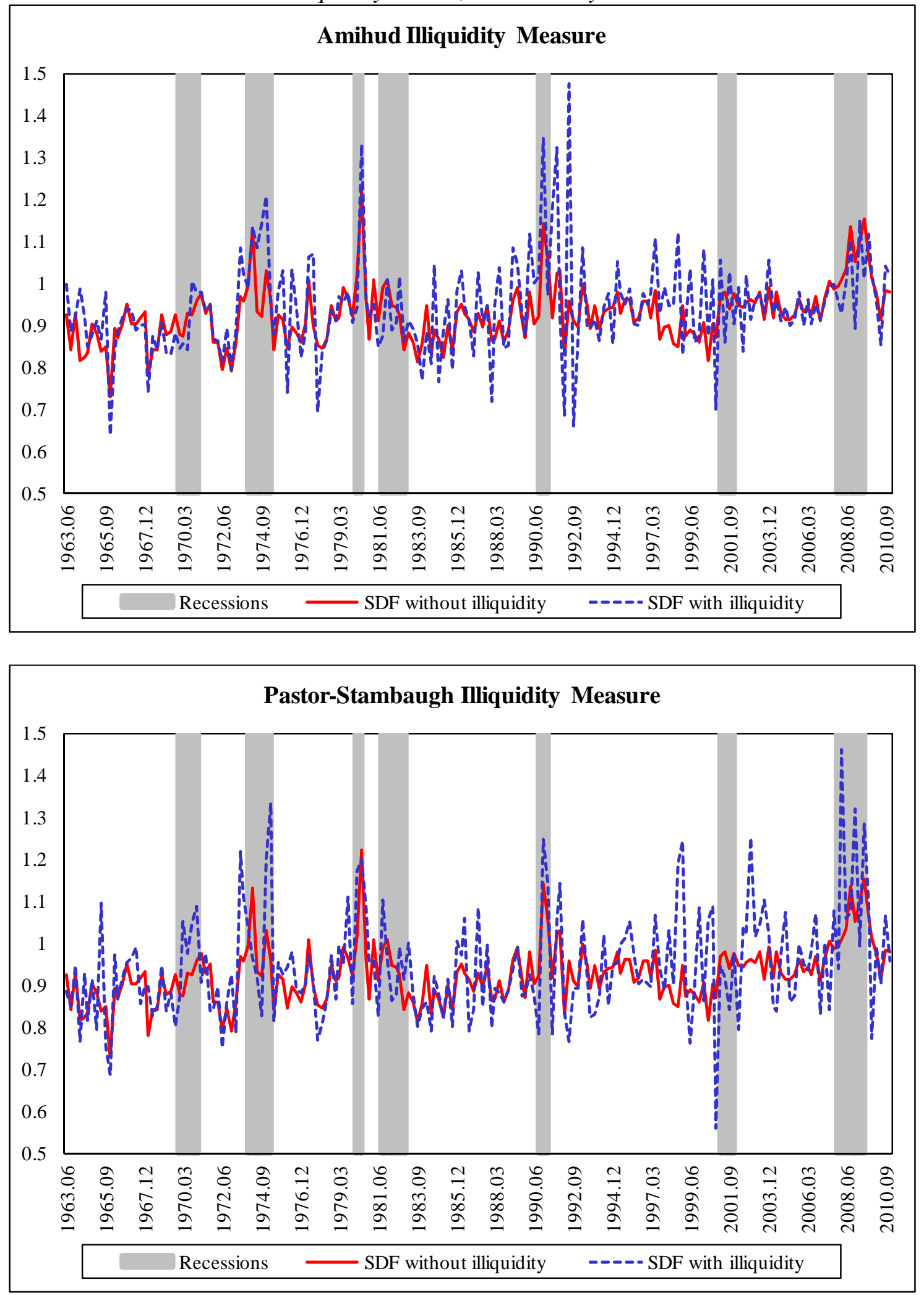
Figure 3.a
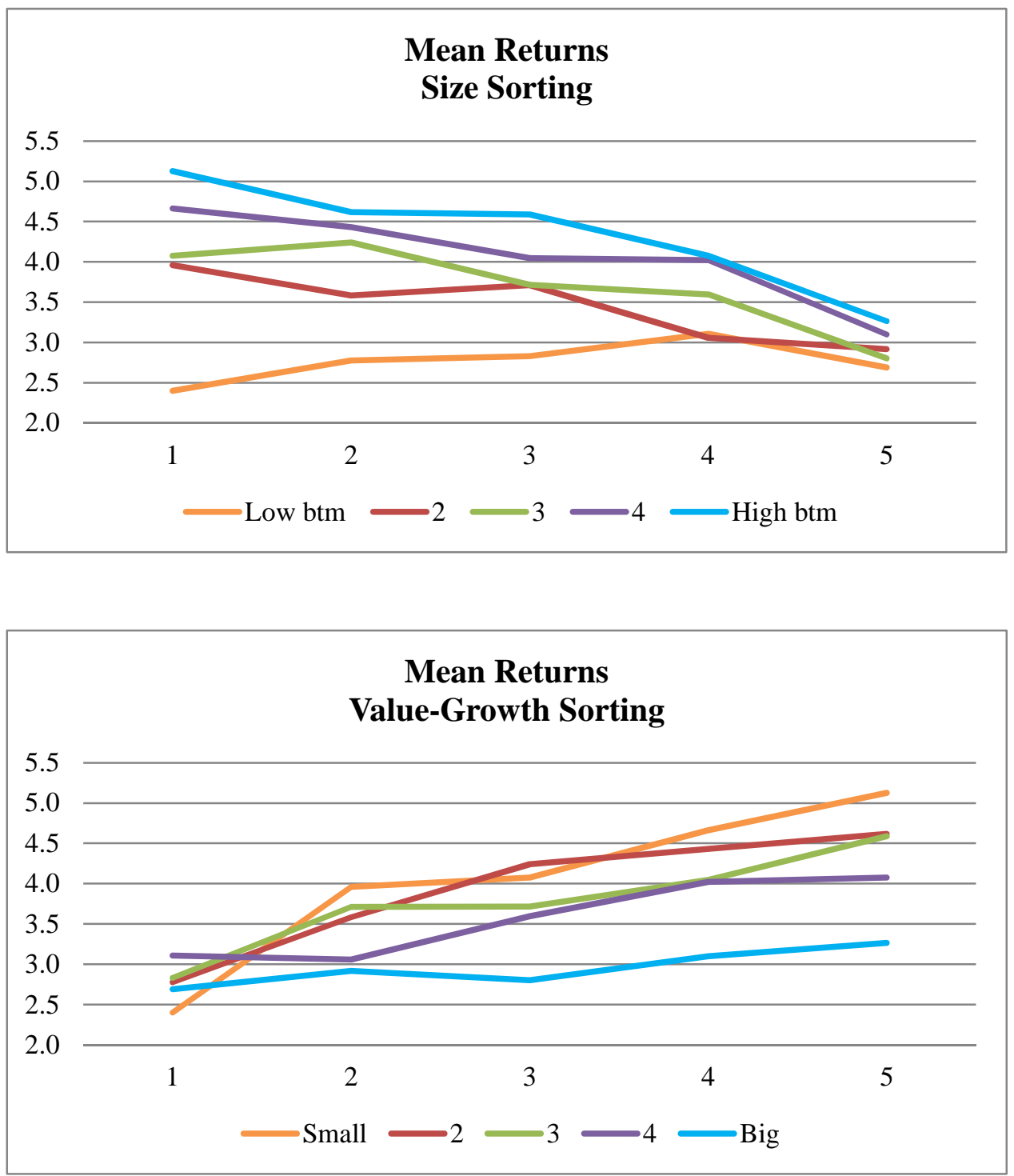
Figure 3.b
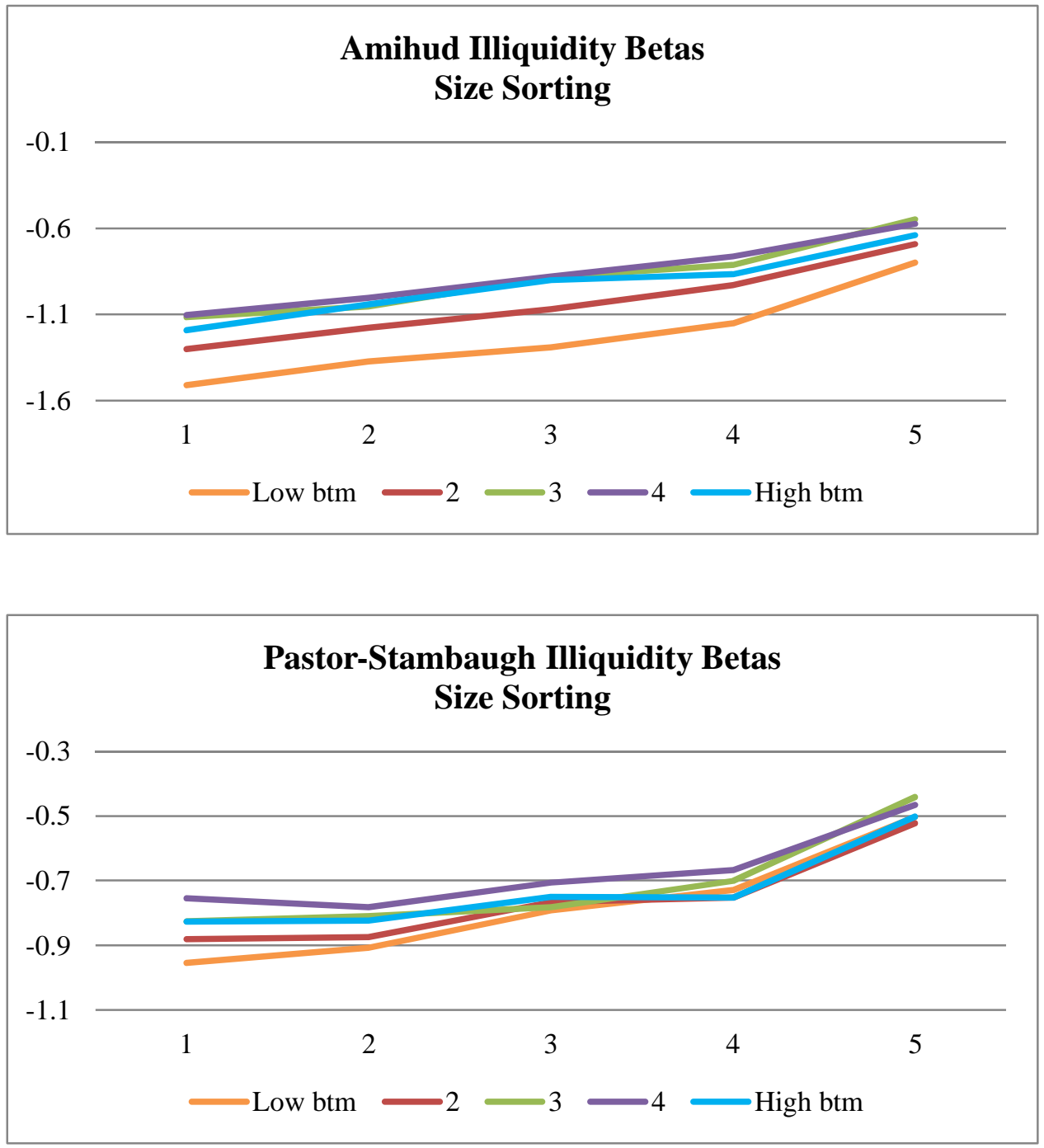
Figure 3.c
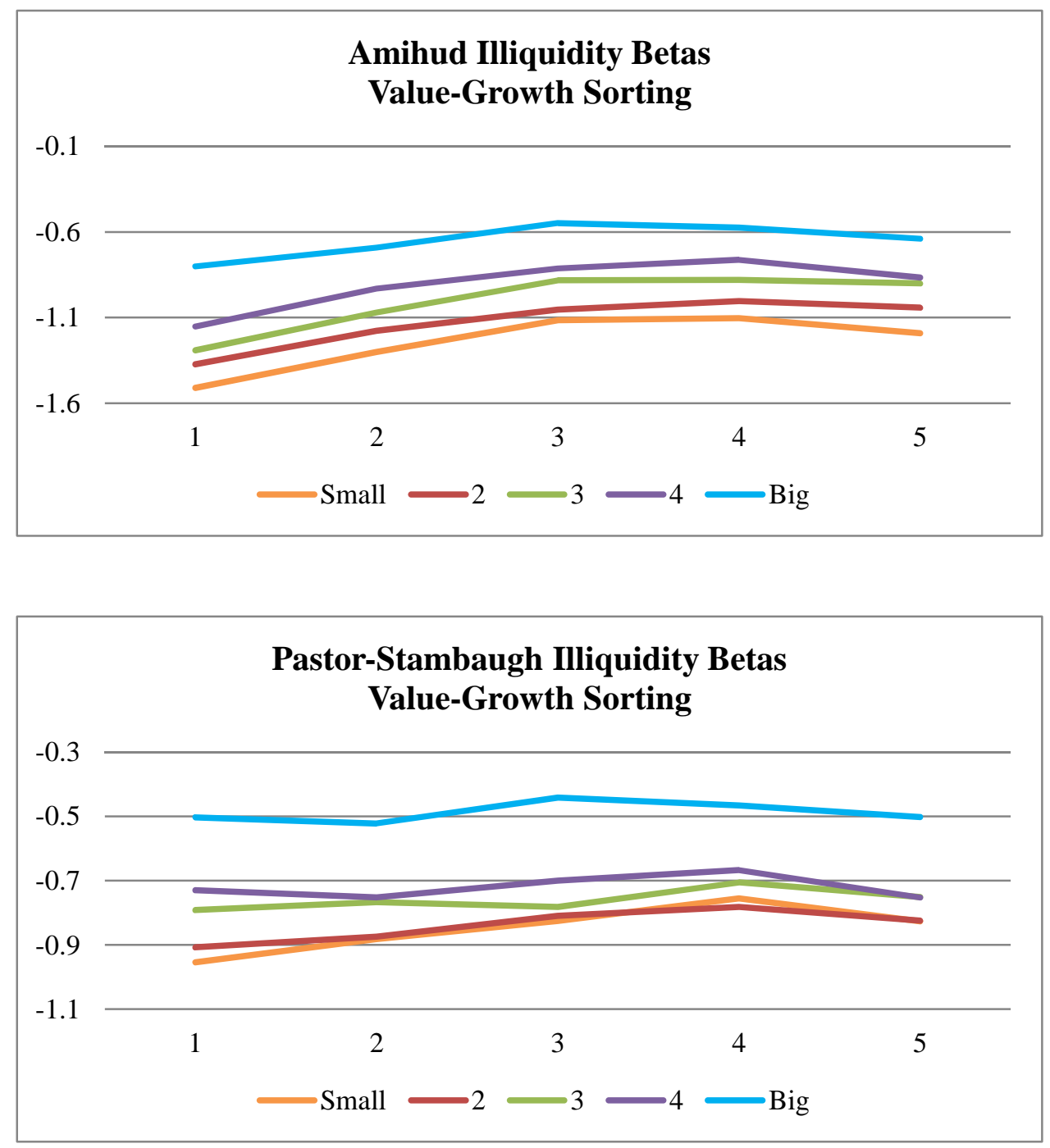
Figure 4

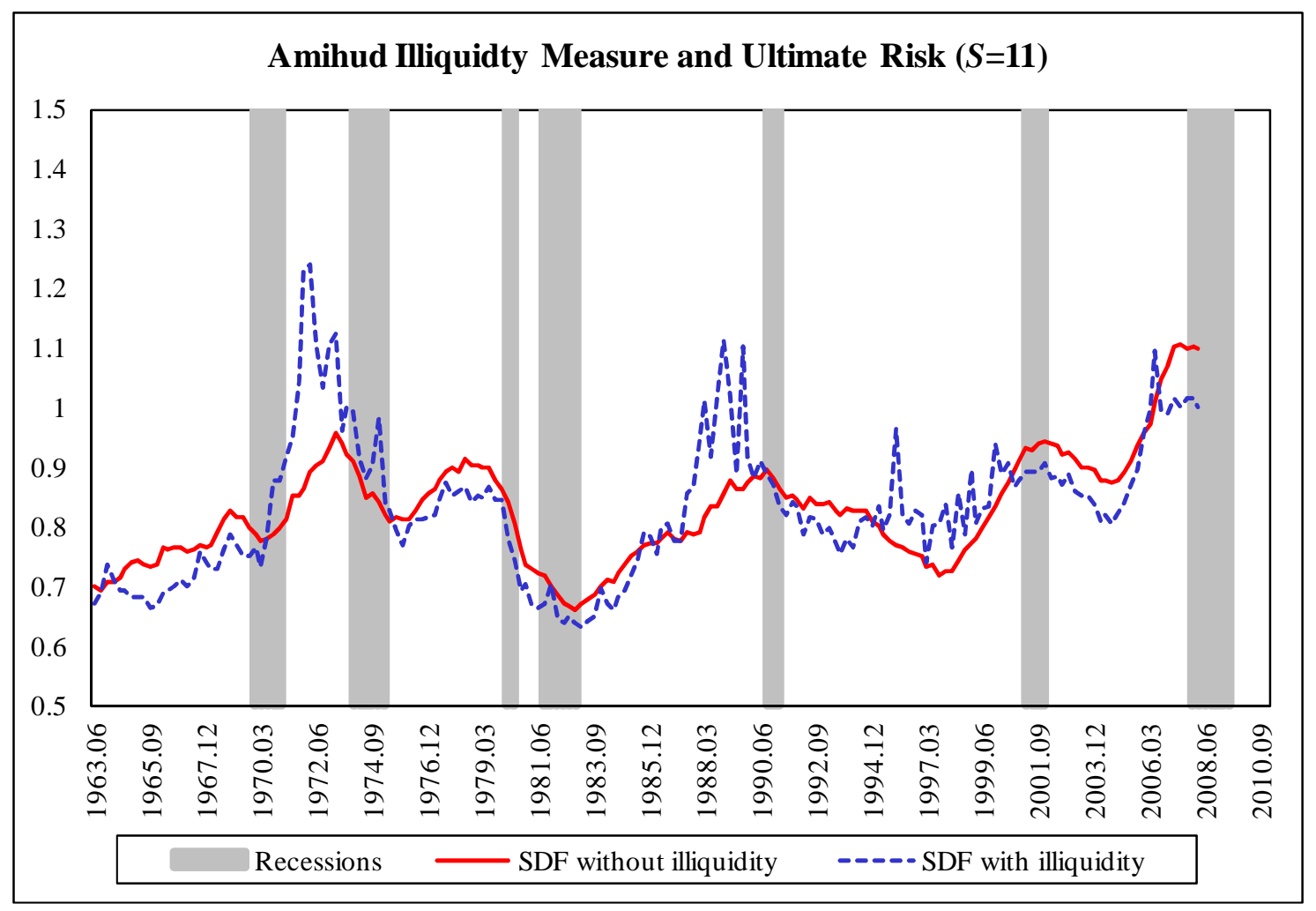




\section{Figure 5}

Mean Adjusted Returns with Recursive Preferences versus Mean Observed Returns Results from Fama-MacBeth Estimation with 25 Fama and French Portfolios

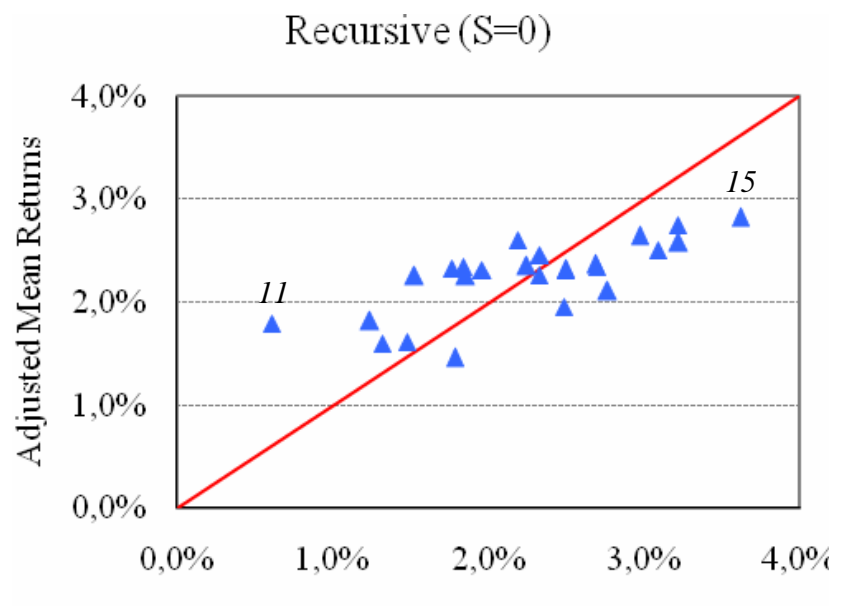

Observed Mean Returns

Recursive with Amihud Illiquidity ( $\mathrm{S}=0$ )

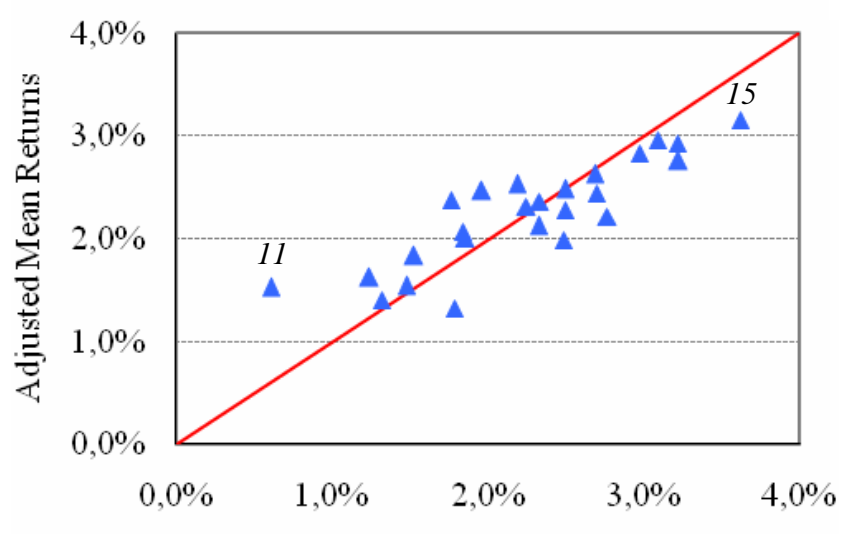

Observed Mean Returns

Recursive with Pastor-Stambaugh Illiq. ( $\mathrm{S}=0)$

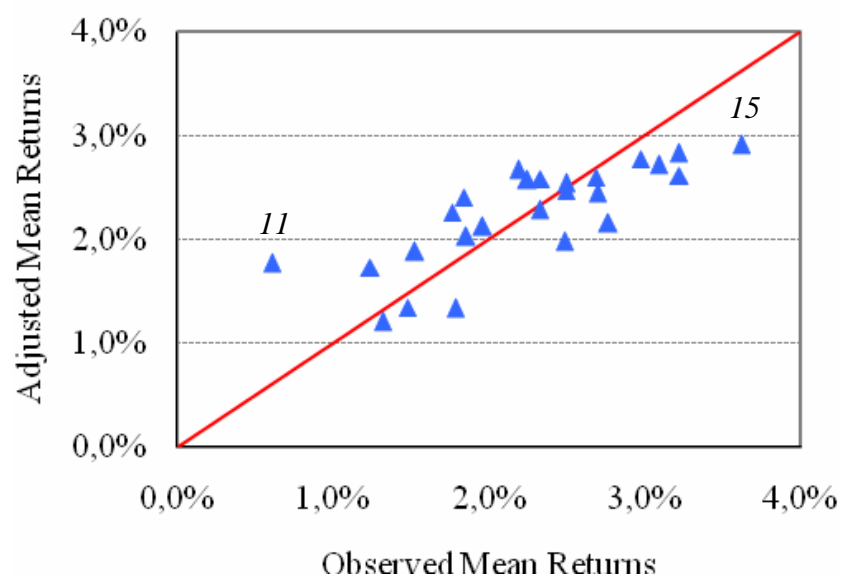

Recursive $(S=11)$

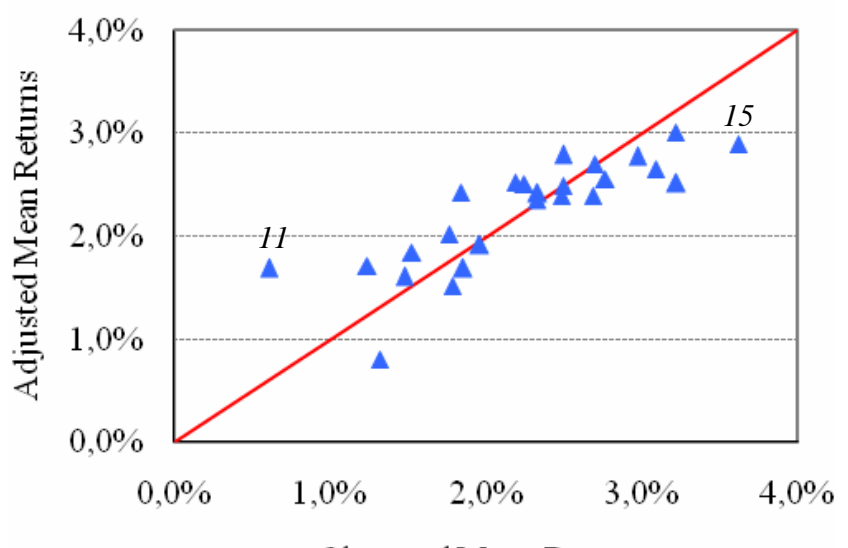

Observed Mean Returns

Recursive and Amihud Illiquidity ( $\mathrm{S}=11$ )

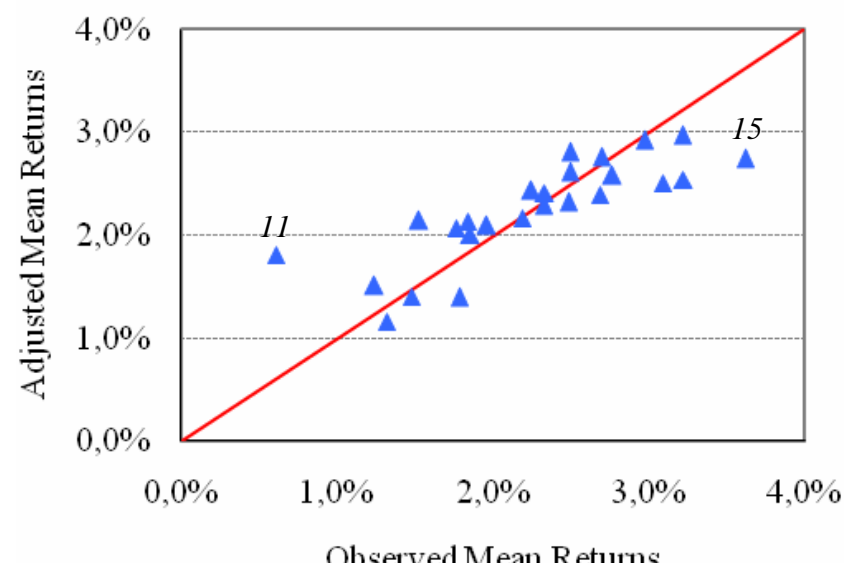

Recursive with Pastor-Stambaugh Illiq ( $\mathrm{S}=11$ )

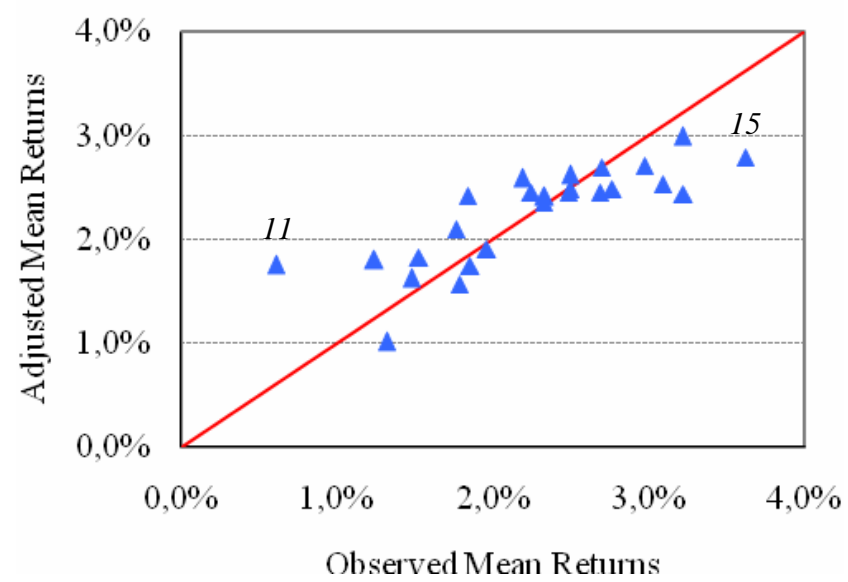

